\title{
Unlocking the Application Potential of Forward Osmosis through Integrated/Hybrid Process
}

\author{
Wei Lun Ang, ${ }^{a, b *}$, Abdul Wahab Mohammad ${ }^{a, b}$, Daniel Johnson ${ }^{c}$, Nidal Hilal ${ }^{c, d}$ \\ ${ }^{\mathrm{a} C e n t r e}$ for Sustainable Process Technology (CESPRO), Faculty of Engineering and Built \\ Environment, Universiti Kebangsaan Malaysia, 43600, Bangi, Selangor, Malaysia \\ ${ }^{\mathrm{b}}$ Chemical Engineering Programme, Faculty of Engineering and Built Environment, \\ Universiti Kebangsaan Malaysia, 43600, Bangi, Selangor, Malaysia \\ ${ }^{\mathrm{c}}$ Centre for Water Advanced Technologies and Environmental Research (CWATER), College \\ of Engineering, Swansea University, Swansea SA1 8EN, UK \\ ${ }^{\mathrm{d} N Y U A D}$ Water Research Center, New York University Abu Dhabi, Abu Dhabi, United \\ Arab Emirates
}

\section{Graphical Abstract}

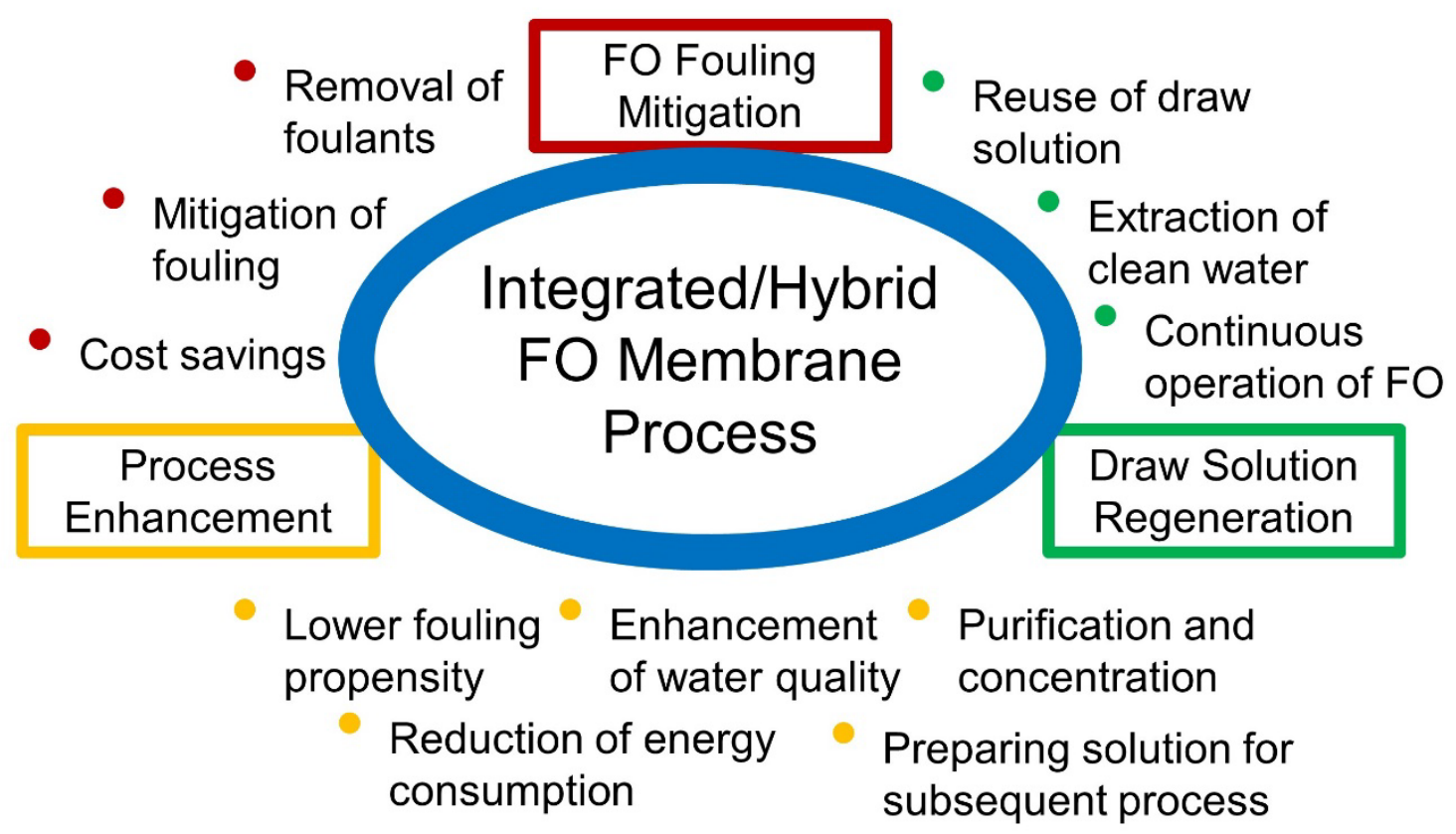

\begin{abstract}
Study of forward osmosis (FO) has been increasing steadily over recent years with applications mainly focusing on desalination and wastewater treatment processes. The working mechanism of FO lies in the natural movement of water between two streams with different osmotic pressure, which makes it useful in concentrating or diluting solutions. FO has rarely been
\end{abstract}


operated as a stand-alone process. Instead, FO processes often appear in a hybrid or integrated form where FO is combined with other treatment technologies to achieve better overall process performance and cost savings. This article aims to provide a comprehensive review on the need for hybridization/integration for FO membrane processes, with emphasis given to process enhancement, draw solution regeneration, and pretreatment for FO fouling mitigation. In general, integrated/hybrid FO processes can reduce the membrane fouling propensity; prepare the solution suitable for subsequent value-added uses and production of renewable energy; lower the costs associated with energy consumption; enhance the quality of treated water; and enable the continuous operation of FO through the regeneration of draw solution. The future potential of FO lies in the success of how it can be hybridized or integrated with other technologies to minimize its own shortcomings, while enhancing the overall performance.

Keywords: forward osmosis; hybrid and integrated process; desalination; wastewater treatment; draw solution; pretreatment

\section{Contents}

Introduction

Definition of Integrated and Hybrid FO Membrane Process

Process Enhancement

- Desalination

- Wastewater Treatment and Reclamation

- Bioproducts and Food Industry

- Energy Generation and Resources Recovery

Draw Solution Regeneration

- Pressure-driven Filtration Processes 
- Temperature-driven Systems

- Magnetic Recovery

- Electrolytic Recovery

- Precipitation of Draw Solute

FO Fouling Mitigation

Future Challenges

Conclusions and Perspectives

\section{Introduction}

In general, a membrane provides a selective barrier which allows the desired substances to pass through while retaining the undesirable substances. This has proved extremely useful in a number of industries. For instance, in the water industries, membranes have been widely employed to produce clean water (for various uses) from different water sources: including surface water, underground water, saline water, and wastewater [1]. In another example, in the food industry, membranes have proven capability in clarifying and concentrating various fruit juices to achieve the desired product quality [2]. In all these cases, the membrane prevents the undesirable compounds, particulates or microorganisms from getting into the final products where the presence of these compounds will limit the usefulness of the treated water or compromise the quality of the final products.

Membrane technologies are generally recognized have shown improvements over older conventional technologies. For instance, ultrafiltration membranes are capable of removing multiple impurities (turbidity, natural organic matter, and microorganism) presence in water sources that would be harmful to human upon consumption [3]. Not only can ultrafiltration membranes remove multiple impurities in one single unit operation (where several 
conventional treatment units are required to achieve this), the removal efficiency and performance stability are much better than the conventional treatment processes such as sand filtration. On the other hand, clarification and concentration of juices by membrane processes could maintain heat-sensitive nutritious compounds in the juices [2]. Conventional thermalbased concentration processes normally will destroy nutritious compounds and give the juices undesirable cooked flavors. These issues become minimal with the use of membrane technologies. In short, the advantages of membrane processes over existing conventional processes have contributed to the increasing acceptance of membranes in various water and food industries.

In general, membranes can be categorized into four different classes based on the size ranges for retained particles or solutes: microfiltration (MF), ultrafiltration (UF), nanofiltration (NF), and reverse osmosis (RO) [4]. A substantial number of existing membrane processes are of the pressure-driven type, where the feed solution will be pressurized to drive permeate flow. These membranes have been further innovatively modified to acquire specific properties for other processes. For example, the enhancement of membrane hydrophobicity for membrane distillation (MD) process where the driving force is due to the temperature difference between the feed solution and product [5]. Forward osmosis (FO) is another interesting membrane process, which is driven by the difference in osmotic pressure between two liquid streams, the reversal of reverse osmosis. For FO, the separation capability of the membrane is approximately similar to NF or RO, yet specialized membranes typically have thinner support layers to enhance back diffusion of the solute to reduce concentration polarization [6].

FO has recently gained considerable attention as an alternative membrane process for various applications. The differences between the FO and the conventional pressure-driven membranes 
97 lie in the working mechanism of both operational modes. FO is driven by diffusive flow of permeate water from a feed stream to a draw solution of higher osmotic potential (Fig. 1). The working principle is a concentration-dilution concept where the stream losing water will be concentrated and the stream gaining water will be diluted. This unique property enables FO to be applied as concentration and dilution processes for many applications, such as juice concentration, saline water dilution, and wastewater concentration, to name a few [7]. Because of the lack of applied hydraulic pressure, the membrane fouling propensity has been generally reported to be lower compared to pressure-driven membranes [8]. However, the commercialization of FO process has been hindered by several challenges.

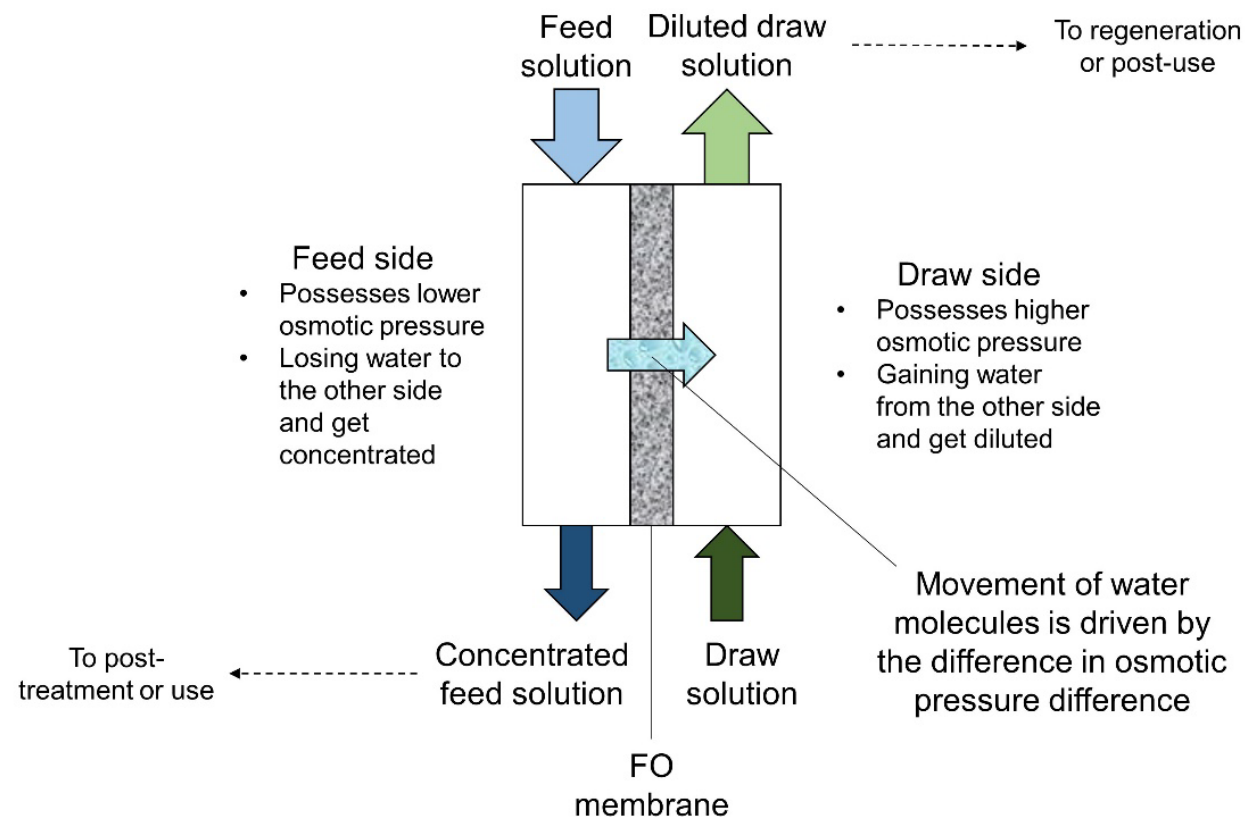

Fig. 1. Working mechanism of FO process.

The first issue associated with FO process is the lack of membranes with suitably high flux and retention. The flux is linked to production capacity, while high retention is necessary to prevent undesirable compounds crossing into other streams. Thus far, the existing advanced FO membranes (mixed matrix, biomimetic, and thin-film composite) still suffer from low water flux and imperfect retention of impurities (compounds in feed solution and ionic salts in draw 
solution) [9]. The second challenge relates to the need of draw solution in order to operate the FO process. Unless the draw solution can be obtained easily (such as industrial brine, concentrated fertilizer, and seawater) or the regeneration of draw solution is unnecessary, the use and regeneration of synthetic draw solution requires an additional unit operation [10]. This incurs additional cost for the FO process. Though FO has been frequently known as a low energy process, this claim is only valid if regeneration of draw solution is not required. Increasing treatment cost will be a major hindrance for the commercialization and acceptance of FO process in the industry. Lastly, FO is rarely operated individually, mainly due to the need for an additional process for draw solution regeneration and clean water extraction from draw solution.

The research on the FO process has not diminished despite the challenges encountered by this technology, with the number of reported articles hitting more than 250 in 2018 [11]. The main category of studies that have been driving the FO research was membrane synthesis and FO application. Considering that a large portion of the reported studies were about application and performance studies, one might question in what way that the FO process can be utilized and be beneficial to the industry, giving the fact that FO could not be operated individually to achieve the application aims. A quick glimpse into the research articles revealed that most of the application and performance evaluation studies of FO have been conducted in integrated or hybrid process form, where the FO process is combined with other technologies to achieve a certain application targets.

\section{Definition of Integrated and Hybrid FO Membrane Process}

A hybrid process is defined as a single system that possesses multiple functions by combining the individual treatment processes while the integrated process is generally categorized as the 
combination of different processes with different functions into a single treatment train $[1,12]$. Though FO process reportedly shows prospective potential in various niche applications, it is generally accepted by the scientific community that a standalone FO process appears to be less attractive and competitive. This shortcoming lies in the operation concept of FO process where it is more to concentration-dilution process and the need of draw solution in most of the applications. To advance the FO process and to realize its prospective application in various industries, innovative design of hybridization and integration involving FO process and other technologies have been actively proposed and sought by the research community. This review paper discussed the studies of the FO process, how it is innovatively hybridized or integrated with other technologies to achieve particular aims and to resolve certain challenges associated with FO or other processes. The hybrid/integrated FO process will be discussed based on three main purposes of having hybridization/integration: process enhancement, draw solution regeneration and fouling mitigation.

\section{Process enhancement}

FO process can be integrated/hybridized with other technologies to enhance the capability of the latter process or to improve the FO performance. The improvement can be in the forms of process efficiency, cost, or minimization of operational problems. In this section, the integrated/hybrid FO process will be discussed based on the main application categories: desalination, wastewater treatment and reclamation, bioproducts and food industry, and energy generation and resources recovery.

\section{$\underline{\text { Desalination }}$}

Desalination is one of the major technologies that is a potential solution to water scarcity. A number of thermal- and non-thermal-based desalination technologies have been developed 
worldwide, with the former technology mainly applied in Middle East countries while the latter (mostly RO membrane desalination) in the rest of the world [13]. Desalination technologies successfully supply clean water to populations, but its operation is still burdened with considerably high energy consumption that drives up the water cost. This particular issue can be attributed to the high salt contents of seawater, which requires more pumping energy to extract the clean water from the seawater as compared to conventional surface waters. In view of this, FO process has been innovatively integrated with desalination technologies to improve the overall performance and cost-practicality of seawater desalination [9]. The main function of the FO process is to provide a platform that enables the dilution of feed to the desalination plant, which subsequently offers the opportunity to lower energy consumption or scaling issue.

Owing to its concentration-dilution working principle, the FO process has been proposed to be integrated prior to seawater reverse osmosis desalination system. The seawater will be fed to the FO process as draw solution and it will be diluted by pulling water from the feed solution that possesses lower osmotic pressure (e.g. low salinity wastewater) $[14,15]$. The osmotic pressure of the diluted seawater will be lowered after passing through the FO process as shown in Fig. 2. The dilution of seawater has a positive impact on the RO desalination process, as the scaling propensity (salts precipitation formation) will be reduced and the lower osmotic pressure can be translated to lower energy consumption (either through lower operating pressure or higher flux productivity). For instance, Yangali-Quintanilla et al. (2011) showed that by using secondary wastewater as feed solution, the FO process can reduce the total dissolved solids (TDS) of Red Sea seawater (draw solution) from $40.5 \mathrm{~g} / \mathrm{L}$ down to $15 \mathrm{~g} / \mathrm{L}$ [14]. The huge reduction in TDS has halved the energy consumption of subsequent low-pressure RO desalination process, making it possible to achieve energy consumption of $1.5 \mathrm{kWh} / \mathrm{m}^{3}$ instead of 2.5-4 $\mathrm{kWh} / \mathrm{m}^{3}$ for standalone RO desalination process. However, this finding is only 
practical if the minimum average FO flux is at $5.5 \mathrm{~L} / \mathrm{m}^{2} . \mathrm{h}$ (the average FO flux in this study was below $3 \mathrm{~L} / \mathrm{m}^{2} . \mathrm{h}$ ). Furthermore, this concept is only practical if the wastewater treatment plant and desalination plant are located close to each other, else the costs associated with transporting and handling the wastewater might be a burden for the operators [16].

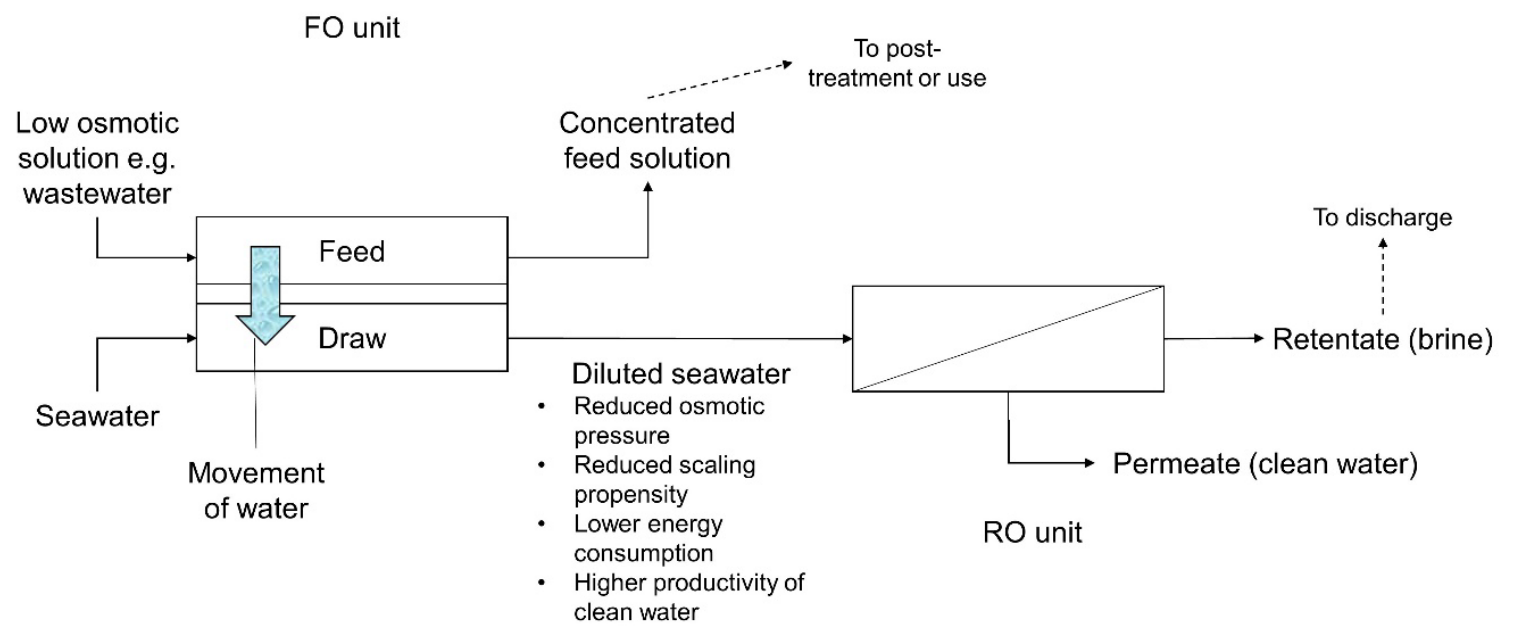

Fig. 2. Integrated FO-RO process for seawater desalination.

A pilot plant consists of integrated FO-RO utilizing wastewater from coal-fired power plant as feed solution to dilute the seawater (draw solution) has been conducted by Choi et al. (2017) for 5 months of operation period [17]. The energy consumption analysis revealed that the energy consumption for desalinating the diluted seawater by FO was $23.3 \%$ less than a typical seawater desalination by RO, with specific energy consumption (SEC) for the integrated FORO at $2.85 \pm 0.05 \mathrm{kWh} / \mathrm{m}^{3}$ and seawater $\mathrm{RO}$ at $3.34 \pm 0.05 \mathrm{kWh} / \mathrm{m}^{3}$. This led the an approximately $15 \%$ lower total energy consumption.

The feasibility of integrated FO-RO process for desalination has also been evaluated via techno-economic evaluation study [18]. Wan et al. (2018) investigated the technical and economic feasibilities of different combination of integrated $\mathrm{RO}$ process, including the arrangement of FO for post-dilution process to dilute and recycle the RO brine and FO as pre- 
dilution process to reduce the RO operating pressure [18]. It was reported that the pre-dilution of FO could reduce the operating pressure of RO (25\% recovery) from 42 bar to 31 bar, resulting in a saving up to $\$ 905,000 / \mathrm{yr}$. For $50 \%$ recovery, the operating expenditure of RO can be further reduced and achieve highest saving up to $\$ 2081,000 / \mathrm{yr}$ when the FO process is integrated with existing RO plant. On another note, the construction of new integrated FO-RO seawater desalination plant can effectively reduce both operating and capital expenditures, with a much higher savings up to $\$ 4390,000 /$ yr. The savings were mostly attributed to the lower RO operating pressure.

Indeed, the economic evaluation done on a similar integrated FO-RO desalination process could only be beneficial if substantial energy and operational costs savings are achieved [19]. Moreover, the threshold flux for FO should be at least $30 \mathrm{~L} / \mathrm{m}^{2} . \mathrm{h}$ to guarantee FO economic sustainability where none of the existing FO membrane has recorded such a high flux value. One of the plausible ways to achieve higher FO flux is to apply pressure at the feed side of the FO process to increase the permeation of water from feed to draw solutions. This operation is known as pressure-assisted forward osmosis (PAFO) where it could increase the overall water recovery and reduce the reverse salt flux of FO process. However, the mechanical strength of the FO membrane and the associated additional energy consumption might be the major challenges for the feasibility of this operation mode. The energy penalty posed by the pressureassisted operational mode could potentially be compensated by enhanced permeate throughput and reduced membrane area [20]. The economic potential of integrated PAFO-RO has been proven higher than integrated FO-RO process, though the plausibility of implementing PAFO to existing RO plants still remain uncertain due to the additional capital expenses associated with PAFO [21]. 
In another study, numerical modelling of integrated FO-RO desalination process has shown that the integrated process performed better than the stand-alone RO process in terms of SEC and recovery rate. At an operating pressure of 30 bar for RO process, the SEC of the integrated system was $2.68 \mathrm{kWh} / \mathrm{m}^{3}$ lower than the stand-alone RO process. In addition, the RO recovery rate of the integrated process was $28 \%$ higher than the stand-alone RO process [15]. These values were acquired after considering the energy consumption associated with the FO process. Such positive outcomes could be obtained as the typical energy-intensive consumption part (regeneration of draw solution) was not required since the diluted seawater was used as the feed for RO process. Similar positive costing analysis has also been reported by Linares et al. (2016) where compared to standalone seawater RO desalination process, the integrated FOlow pressure RO process recorded 56\% lower operational costs (due to savings in energy consumption and fouling control) and $16 \%$ lower total water cost per cubic meter of water produced [22]. Pilot-tested of real desalination plant has also been constructed and it was reported that compared to conventional seawater RO desalination system, the integrated FO process (draw solution and regeneration technique were kept confidential by the company) could be operated at about $60 \%$ of the energy consumption of the competing seawater RO facility [23].

Similar integration configuration has also been tested for the thermal-based desalination process. FO process was integrated with multi-stage flashing (MSF) desalination where the brine reject from real MSF desalination plant and seawater were used as the draw and feed solutions, respectively [24]. It has to be noted that the brine reject from MSF is normally recycled back to the evaporator, meaning that the system is vulnerable to high scaling propensity (formation of salt precipitates) due to the accumulation of divalent salts such as calcium, magnesium and sulfate. To prevent scale deposition in the MSF plant, the brine reject 
was diluted through FO process since its osmotic pressure was higher than seawater feed solution. An experimental study with real samples has indicated that 3-9\% of brine reject dilution was achievable, depending on the operating temperature. The findings supported the theoretical simulation studies where FO can be used as a medium to dilute the brine reject [25]. Dilution of brine reject will potentially lower down the scaling deposition propensity in the MSF plant and increase the overall recovery rate. Further pilot plant test is required to prove the practicality of the integrated FO-MSF desalination process and to verify the increment of recovery rate contributed by FO process.

The FO process has also been proposed to be integrated with processes such as nanofiltration and electrodialysis for seawater and brackish water desalination purposes [26-29]. Both experimental and simulation modelling studies have shown that the integration of FO managed to dilute the feed water for subsequent nanofiltration and electrodialysis desalination. These integrated processes can produce permeate water meeting drinking water standards. For instance, the optimization simulation done by Bitaw et al. (2016) showed that FO could be integrated prior the electrodialysis process to provide good feed water for more efficient electrodialysis desalination process [28]. Since the FO process was utilizing draw solution in the operation, it provided an access to a wide range of ionic species with higher mobility than $\mathrm{NaCl}$ and other trace ions in seawater. The use of $\mathrm{FO}$ draw solution as feed for electrodialysis resulted in lower electrical resistance for electrodialysis operation and eliminated the risk of membrane fouling issue. Economic feasibility analysis revealed that the use of ammonium chloride as draw solution for FO process could give the lowest total unit product water cost with $0.51 \mathrm{USD} / \mathrm{m}^{3}$ for the integrated FO-electrodialysis-RO process, which was much lower than existing seawater RO desalination system. However, the practicality and up-scaling of 
these processes remain uncertain as only limited literature, especially on costing aspects, is available.

Besides being integrated as a pretreatment prior to other main desalination technologies, FO has also been proposed to be integrated after the desalination technologies to achieve zeroliquid discharge treatment system [30]. Utilizing a thermolytic draw solution, FO can further concentrate the brine discharged from seawater RO desalination plant before being sent to a crystallizer. The crystallizer will precipitate the salts, while the diluted draw solution will be regenerated using low-temperature distillation processes. This helped to close the loop of a desalination process and is especially suitable for inland brackish desalination plants where the discharge of brine is unfavorable due to its disruptive effects on the local environment.

\section{$\underline{\text { Wastewater Treatment and Reclamation }}$}

Wastewater is defined as any water where the quality has been affected by human use (from sources such as domestic, industrial, commercial, and agricultural activities), from surface runoff (stormwater), and sewer inflow or sewer infiltration [31]. The characteristics and constituents of wastewater vary depending on the sources, which may be harmful to the environment and living organism if left untreated and disposed to the waterways. Generally, the treatment of wastewater can be divided into three broad categories: physical, biological, and chemical; according to the main working mechanism [12]. Among these technologies, membrane has emerged as one of the most promising physical treatment processes and has a proven track record in various wastewater treatment systems [32]. Membrane processes are not only more effective than conventional processes but its versatility lies in the capability to be integrated or hybridized with other treatment technologies, giving the whole treatment system greater capability in removing multiple undesired pollutants [33]. Similar to conventional 
pressurized-membrane processes, FO has also found its potential in wastewater treatment processes, where it can be used for concentration: reducing the amount of wastewater or extracting clean water from the wastewater by using draw solution. Integrated/hybrid FO process will be discussed based on the following categories: hybrid FO process (combining several processes into one treatment unit) and FO process integrated with other technologies for treatment or clean water extraction (regeneration of draw solution) purposes.

Membrane bioreactor (MBR) is a hybrid membrane process that combines microfiltration or ultrafiltration with a biological wastewater treatment process, such as activated sludge. MBR is now being widely used for municipal and industrial wastewater treatment for treatment and non-potable reuse applications. The better quality of treated water and consistent treatment efficiency in a smaller footprint as compared to conventional treatment processes are some of the main reasons for the wide acceptance of this hybrid membrane process [34]. However, the treated water may still contain low molecular weight constituents, such as trace organic compounds (TrOCs), ions, and viruses that are hardly rejected by microfiltration or ultrafiltration membranes [35]. To enhance the quality of the treated water without exerting additional cost (energy) or exacerbating the membrane fouling propensity, FO membrane has been proposed as a replacement for microfiltration and ultrafiltration in MBR. The new hybrid process - osmotic membrane bioreactor $(\mathrm{OMBR})$ can produce treated water with a lower concentration of low molecular weight impurities, since FO membrane has better retention capability compared to MF or UF [36]. OMBR can be operated in two modes - with FO membrane placed inside or outside the bioreactor, as shown in Fig. 3 [37]. The draw solution will extract water from the bioreactor fed with wastewater. An additional process will have to be applied for water reclamation and regeneration of draw solution. 


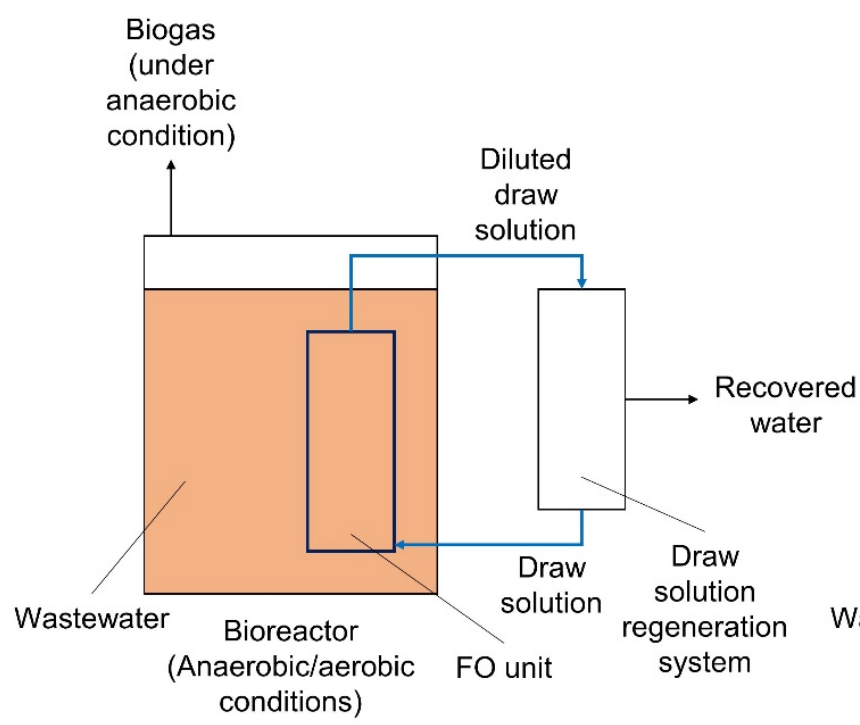

(a)

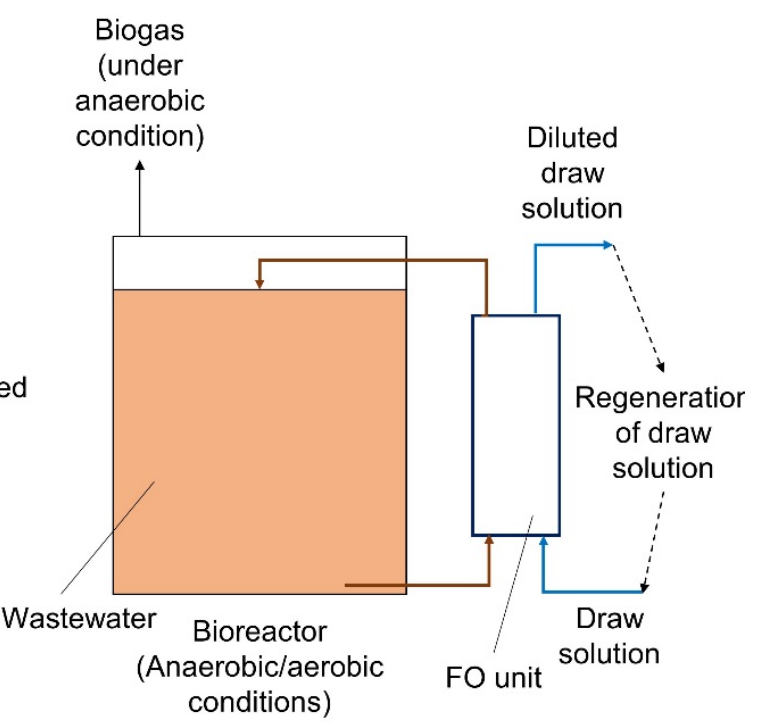

(b)

332 Fig. 3. Schematic diagram of OMBR (a) FO submerged in the bioreactor; (b) side-stream 333 drawn out for FO unit (adapted from [37]).

The performance of OMBR has been actively investigated, with promising results indicating the potential of OMBR for various wastewater sources [38]. Improvement in terms of rejection of TrOCs, nutrients, and organic substances has been achieved with the incorporation of FO in the conventional MBR process [36,38]. In addition, OMBR has also been employed to increase the solid concentration for anaerobic digestion [39]. The dewatering capability of FO enabled water to be continuously drawn out from the bioreactor and led to the concentration of solid contents. As the total solids content in the bioreactor was gradually increased, the associated methane (biogas) production and organic degradation have also been enhanced. This implies the potential of the FO process in enhancing the performance of anaerobic digestion (for biogas production) while operating in a smaller footprint and at the same time supporting the effort for sustainable wastewater management [40]. Also, the concentration of anaerobically treated wastewater by FO process could lead to the enrichment of nutrients (especially phosphorus) in

347 the wastewater and subsequently to be recovered as struvite crystal [41]. However, the high 
retention of pollutants by the FO membrane indicates that the pollutants will have a high tendency to be accumulated and concentrated in the bioreactor. Reverse diffusion of draw solution would also contaminate the bioreactor with draw solutes. Past studies have demonstrated that the accumulation of pollutants or the presence of draw solutes in the bioreactor will affect the microbial activity (biodegradation of pollutants), resulting in lower treatment efficiency (e.g. nutrients removal and organic matter degradation) of the hybrid process $[38,42]$. The build-up of salinity in the bioreactor will also reduce the FO membrane flux since the osmotic pressure difference between the feed and draw solutions has been lessened.

To overcome these issues, the OMBR process has been integrated with either MF or UF membranes to continuously draw out a portion of water from the bioreactor [38,43-46]. For instance, OMBR integrated with MF (MF-OMBR) could achieve a long-term continuous operation with high methane (biogas) production from the anaerobic bioreactor due to the consistent salt level [45]. The water drawn out by MF membrane prevented salt accumulation in the reactor and can be further treated or processed to recover the phosphorus nutrient. The additional benefit was that the FO membrane flux could be maintained since the osmotic pressure difference between the wastewater and draw solution has remained constant. A longterm pilot scale of UF-OMBR process has further confirmed the benefits of integrating UF process in the typical OMBR system [47]. The integrated system managed to operate for more than 120 days while consistently producing high quality RO permeate (draw solution regeneration) from domestic wastewater. The FO membrane recorded a stable flux of 4.8 $\mathrm{L} / \mathrm{m}^{2}$.h with minimal flux decline throughout the whole operation period. Though the proposed approach seems to resolve part of the issues associated with OMBR, the issues of effluent 
quality from UF or MF membranes and the FO membrane fouling needs to be taken into consideration before the integrated OMBR process can be applied commercially.

Since the FO membrane is exposed to wastewater laden with an abundance of suspended solids and impurities, it is vulnerable to organic fouling of the membrane surface. In order to eliminate the membrane fouling issues, Qiu et al. (2016) replaced the MF membrane with biofilm (BFOMBR) for the treatment of municipal wastewater [48]. The side-stream effluent from the bioreactor was drawn out without any filtration process and hence recorded slightly lower removal of organic matter and nitrogen. Despite the comparatively lower removal of impurities, the incorporation of fixed-bed biofilm mitigated the FO membrane fouling by $25-55 \%$ as compared to MF-OMBR. The improvement of FO performance could be attributed to the washing-out of suspended growth and dispersed cells in the reactor (due to the absence of MF membrane), leaving behind the attached growth of the biofilm. Subsequently, the deposition of impurities on the FO membrane has also been minimized in the case of BF-OMBR. Modification of OMBR has also been done by Juntawang et al. (2019) where the bacteria in the reactor was grown and entrapped within a polymeric matrix [49]. The entrapped bacteria in the anaerobic reactor was more resistance to the effect of reverse salt flux as compared to the suspended cells found in a typical OMBR. The salt stress will lead to cell dehydration and the release of extracellular polymeric substances and soluble microbial products, two substances that are normally associated with membrane fouling in MBR [50,51]. This might explain why the entrapped cells OMBR showed a lower FO membrane fouling propensity, since the bacteria were more resistant to salt stress leading to lower release of extracellular polymeric substances and soluble microbial products (13-68\%). 
FO can also be integrated with other technologies such as coagulation, microfiltration, adsorption, ultrafiltration, electrocoagulation, multimedia filtration, and electrochemical processes [52-58]. Each integrated process serves a different purpose, be it improving the conditions of the feed water for FO process or increasing the pollutant removal efficiency of the whole treatment system. For instance, the incorporation of electrocoagulation has managed to remove the total organic carbon and total suspended solids up to $78 \%$ and $96 \%$, respectively, the two main pollutants present in produced water that could severely foul the FO membrane [57,59]. The installation of MF membrane prior to FO process has also succeeded in removing the total organic carbon $(\sim 52 \%)$ and turbidity $(\sim 98.5 \%)$ in fracking wastewater [58]. In these cases, FO membrane performance was stable with minimal fouling due to the reduction of impurities in the feed solutions. Consequently, clean water can be extracted while draw solution can be regenerated through the downstream MD process.

A considerable number of studies have been made of the FO process integrated with membrane technologies (especially MD and RO) to regenerate the draw solution and to recover the extracted clean water [60-69]. In this integrated process, FO was used to extract water from various wastewater sources, such as sewage, produced water, human urine, effluent from the leather industry, and coal mine wastewater, to name a few. The volume of the wastewater would be reduced due to concentration process by FO, which would be beneficial in terms of space management and handling cost. On the other hand, the diluted draw solution needs to be regenerated or else the FO process will fail to operate (low osmotic pressure difference will lead to low water flux). Hence, the integration of $\mathrm{FO}$ with other technologies for draw solution regeneration is vital to ensure the continuous operation of FO process and extraction of clean water. 
421 In another case, the regeneration of draw solution was eliminated with the use of fertilizer as

422 the draw solution. Chekli et al. (2017) reported that the FO process could be used to concentrate

423 the synthetic wastewater with fertilizer as the draw solution, though the FO process has to be

424 integrated with pressure assisted osmosis (similar operation as FO process but the feed stream

425 was subjected to 2 bar of pressure) to further dilute the fertilizer draw solution to the level

426 suitable for hydroponic application [70]. Preliminary assessment of energy and cost analysis

427 showed that by combining both the FO process and pressure assisted osmosis could lead to

428 reduction in membrane replacement cost, albeit the overall operating cost was slightly higher

429 (due to the additional energy requirement for pressure assisted osmosis process) than

430 standalone process. This indicated the trade-off between the different aspects when designing the integrated process for optimal energy and expenditure costs.

Bioproducts and Food Industry

Concentration technology is an important process in various industries to obtain products with desirable quality and to save costs associated with shelf life, storage, and transportation. For instance, fruit juices are generally concentrated from raw juices to increase their shelf life and to save space for storage and cost for transportation [71-73]. The typical technologies employed for fruit juices concentration are multi-stage vacuum evaporation, freezing technique, and membrane (NF \& RO) processes. These processes possess some drawbacks, such as being energy-intensive, have negative impacts on juice quality, and high membrane fouling issues [74]. Currently, FO has been proposed as an alternative technology for fruit juice concentration, aligns with its working principles [75]. Though numerous studies have demonstrated the capability of FO in concentrating the fruit juices to a desirable concentration, studies on integrated FO process for this application have been rare. An integrated FO process reported in the literature was the integration of FO with MD where the latter process served to regenerate 
the draw solution and to ensure continuous operation of FO process [74]. The integrated FO-

447 MD process managed to increase the total soluble solid of apple juice from $10.6^{\circ}$ Brix to $45.1^{\circ}$ Brix, which was twice the value achieved by an RO concentration process. The nutrition loss was minimal and the presence of draw solute - potassium sorbate (food preservative) in the concentrated juice was far below the allowed level in food industry. This study showed that the integrated FO process may have practical application potentials in the juices concentration process.

In the production of Greek-Style Yogurt, a considerable amount of Greek yoghurt Acid Whey (GAW) is also produced. GAW can be disposed as wastewater after proper treatment, but also contains some milk solids (proteins, lactose, and minerals), which can be recovered and used as ingredients in value-added products such as beverages, sauces, snacks or baked goods [76]. However, the concentration of these useful substances was low (approximately 6\%), making it difficult to be processed, stored, or transported. In view of this, non-thermal concentration processes such as RO have been utilized to concentrate the solution by removing water. Unfortunately, the application of RO process revealed drawbacks such as high membrane fouling and limited attainable concentration due to concentration polarization. In this context, Menchik et al. (2019) have integrated RO and FO processes to concentrate GAW [76]. The GAW was first concentrated by RO from initial total soluble solid of $6.6^{\circ}$ Brix to $19.6^{\circ}$ Brix where the pre-concentrated GAW was then further concentrated by FO process to acquire a total soluble solid of $40.2^{\circ}$ Brix. The role of FO was to further concentrate the GAW as the limitation of concentration has been achieved for $\mathrm{RO}$ and no further concentration is possible due to high concentration polarization and membrane fouling. With the integrated RO-FO process, the GAW attained the concentration levels comparable or higher than thermal 
evaporation. More encouraging was that the integrated membrane process did not cause any thermal damage on the GAW concentrate.

In another similar application, the costing analysis of water recovery and whey powder production from cheese whey waste using integrated FO process has also been conducted. This is especially important as the FO process has been argued to increase the costs considerably due to the need for draw solution regeneration. By using process modeling and cost estimation software program, Aydiner et al. (2014) reported that the integrated FO-RO process managed to achieve the highest water recovery (from the regeneration of draw solution through RO system) at $77 \%$ and possess payback period at par with the conventional UF-RO process for the concentration of whey and water recovery [77]. Such positive techno-economic finding could be attributed to the better whey concentration efficiency by FO as compared to UF, which subsequently led to higher whey powder production rate (translated to higher revenue from whey powder sale) in the downstream process. The techno-economic evaluation was proceeded by replacing the RO with MD for the regeneration of draw solution. The payback time of the investment for integrated FO-MD process in dairy wastewater treatment was less than 1 year due to annual revenues of about 3.4 million $\$$ from water recovery and whey powder selling [78]. This further strengthened the role of integrated FO process in promoting sustainable waste management with good economic benefits.

Integrated FO process has also been applied for protein concentration. Proteins (and other biopolymers) have a wide range of commercial applications in nutraceutical, medical, and pharmaceutical markets [79]. Since most proteins are labile and sensitive to heat, non-thermal separation and purification are required for their concentration. Ling et al. (2011) proposed a dual-stage FO system for protein enrichment using nanoparticles capped with polyacrylic acid 
as the draw solution [80]. The protein solution was concentrated in the first FO stage while the regeneration of draw solution was conducted in the second FO stage with synthetic RO brine to regenerate the nanoparticle draw solution. It was reported that the protein molecules remained intact and stable during the enrichment process which could be attributed to the minimal reverse salt flux. The success of this indicates that integrated FO process can be used for the application of other pharmaceutical and bio-molecule concentration and purification processes.

Bioenergy has emerged as a source of renewable energy. It can be produced from easily available waste materials, such as the liquid fraction from hydrothermal pretreatment of rice straw that contains sugar, which is the nutrient source for the production of bioethanol through fermentation process [81]. However, the concentration of sugar in the liquid fraction was too low for efficient bioethanol production. The production efficiency was further reduced with the presence of fermentation inhibitors. To facilitate more efficient production of bioethanol, FO has been adopted to concentrate the liquid fraction before the fermentation process [82]. FO was used to increase the sugar concentration in the liquid fraction (feed solution) while at the same time maintaining the concentration of fermentation inhibitors in the feed solution at a steady state by only partially rejecting the inhibitors. The increase of sugar concentration and ratio of sugar to fermentation inhibitors resulted in a higher yield of ethanol from fermentation, with a yield of $18 \mathrm{~g} / \mathrm{L}$ achieved as compared to $4.83 \mathrm{~g} / \mathrm{L}$ with liquid fraction without concentration process. These results show that FO can be incorporated prior to the fermentation process to concentrate the sugar content and increase the bioethanol production efficiency.

A similar concept has also been applied to the recovery of succinic acid from the fermentation broth. Succinic acid serves as precursor or starting material for many industrial valuable 
520

521

522

523

524

525

526

527

528

529

530

531

532

533

534

535

536

FO unit

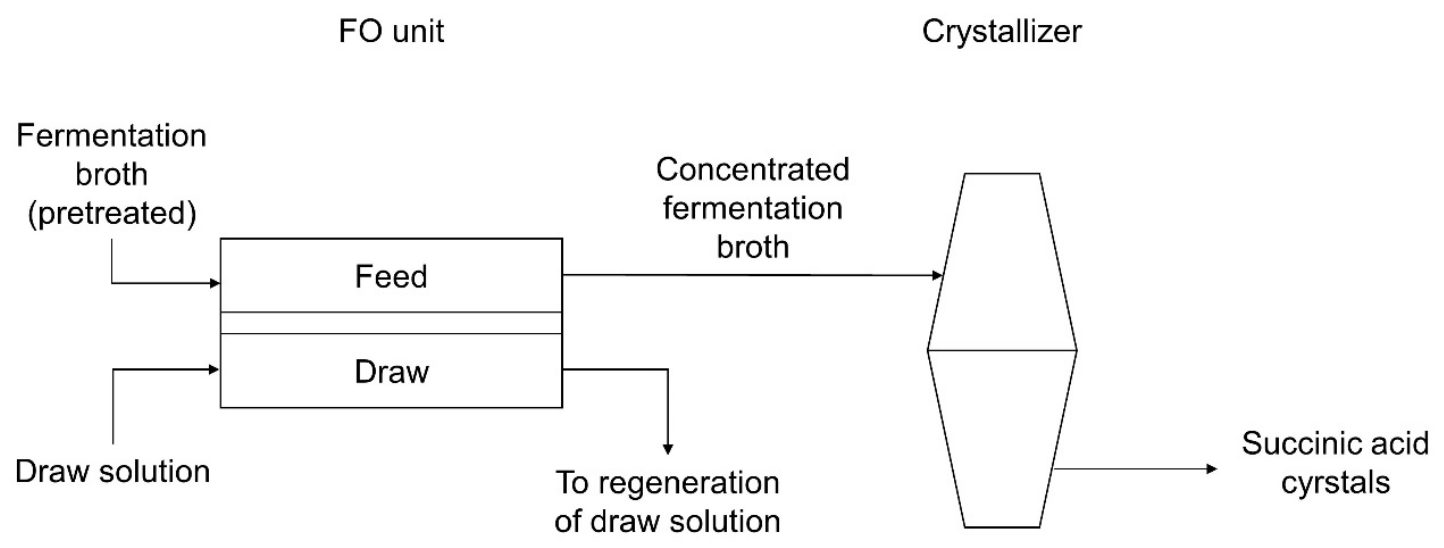

products, such as for food, pharmaceuticals, green solvent and biodegradable plastics [83].

Conventionally, succinic acid is synthesized through a chemical process using non-renewable materials (liquefied petroleum gas or petroleum oil). This synthetic approach and the starting materials are not environmentally friendly [84]. Hence, the sustainable production of succinic acid through the use of fermentation-based route was developed to harvest the succinic acid from easily available raw materials and using a less-hazardous synthesis process. Though fermentation can produce succinic acid, its concentration is too low for cost-effective extraction of succinic acid from the broth. In this case, FO membrane process was integrated prior the crystallization process to concentrate the succinic acid such that the concentration was suitable for crystallization to take place (Fig. 4) [85]. It was reported that FO managed to concentrate the succinic acid present in the real fermentation broth from $28.88 \mathrm{~g} / \mathrm{L}$ to $111.26 \mathrm{~g} / \mathrm{L}$, with the retention of succinic acid in the feed solution as high as $99 \%$. The concentrated fermentation broth was then crystalized to obtain succinic acid crystals, with the purity and yield recorded at $90.52 \%$ and $67.09 \%$, respectively. Without FO concentration, none of the succinic acid crystals was found due to the low concentration and presence of impurities. Hence, the findings indicated that the FO process can help to materialize the sustainable production of succinic acid by concentrating the solution to the level suitable for crystallization process.
537

538

539

Fig. 4. Integrated FO-crystallizer for the purification of succinic acid from fermentation broth (adapted from [85]). 
$541 \quad$ Energy Generation and Resources Recovery

542 The FO membrane process has also found a potential role in energy generation by enhancing 543 the performance of renewable energy production through methane (biogas). One typical 544 integrated process is the combination of FO with anaerobic digestion (as in the form of MBR) where FO helps to prepare the feed solution at optimal conditions for biogas production. The FO process in OMBR extracted water from the bioreactor and at the same time led to the concentration of solid contents in the bioreactor [40]. With more concentrated solid contents, the biodegradation of organic contaminants would also be enhanced. Consequently, the increase of bacterial activity also led to the rise of biogas production.

550

551 Another emerging technology for renewable energy production is through pressure retarded osmosis (PRO) process. PRO utilizes the movement of water from low-salinity feed solution across a membrane to a high-salinity draw solution against a hydraulic pressure for the harvesting of renewable salinity-gradient energy [86]. Despite the great potential shown by PRO in generating energy, membrane fouling still remains as one of the most challenging issues prohibiting the commercial application of PRO technology. To alleviate the membrane fouling issue, Cheng et al. (2018) have proposed to install FO as a pretreatment step prior to the PRO process (Fig. 5) [87]. In this context, wastewater retentate from a municipal water recycling plant was used as the feed solution while the draw solution was $\mathrm{NaCl}$ solution. Upon

560 dilution, the draw solution would be sent to the PRO system as feed while seawater brine was used as the draw solution. In this operating mode, direct contact of wastewater with the PRO membrane was prevented, and subsequently the issue of PRO membrane fouling could be reduced. 
FO unit $\quad$ PRO unit

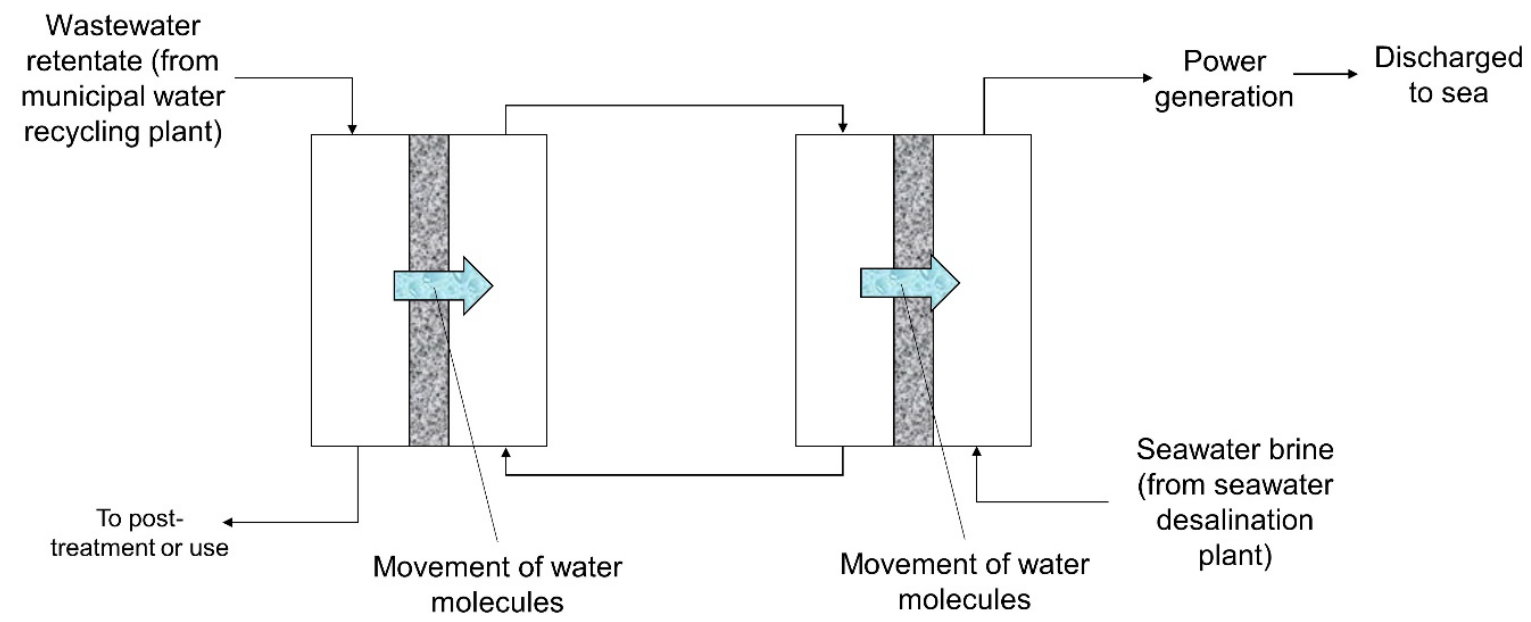

Fig. 5. Integrated FO-PRO process for power generation (adapted from [87]).

567 Bioelectrochemical systems such as microbial fuel cells and microbial electrolysis cells have emerged as one of the multipurpose processes for renewable energy production and wastewater treatment. The concept is developed where the microorganism in the anode of the cells will oxidize the organic substances present in the wastewater (biodegradation of wastewater), and the generated electrons can be used to produce electricity [88]. However, bioelectrochemical systems encounter several limitations for commercial applications, such as low electricity production and the treated water requires further treatment before it can be safely discharged [89]. To resolve these issues, the integration of a bioelectrochemical process with FO was explored. Liu et al. (2017) have shown that by integrating microbial fuel cells with anaerobic acidification and an FO membrane process, the bio-electricity production and clean water recovery for low-strength wastewater have been successfully enhanced [90]. The improvement of performance was attributed to the role played by FO process where it concentrated the ethanol and acetic acids (produced through anaerobic acidification process) in the bioreactor

580 (as shown in Fig. 6), preparing the solution easier to be used by the exoelectrogens to produce electricity based on the fact that the simple substrates were more easily utilized for power 
582

583

584

585

586

587

588

591

592

593

594

595

596

597

598

generation [91]. Another factor that contributed to enhanced electricity production was the controlled salt concentration in the bioreactor. MF membrane process was installed to consistently draw out the solution in the bioreactor to maintain a healthy salt concentration for the growth of microorganism and electricity production. The extracted effluent possessed a good quality with more than $97 \%$ removal of organic matters and total phosphorus, which could be used for toilet-flushing.

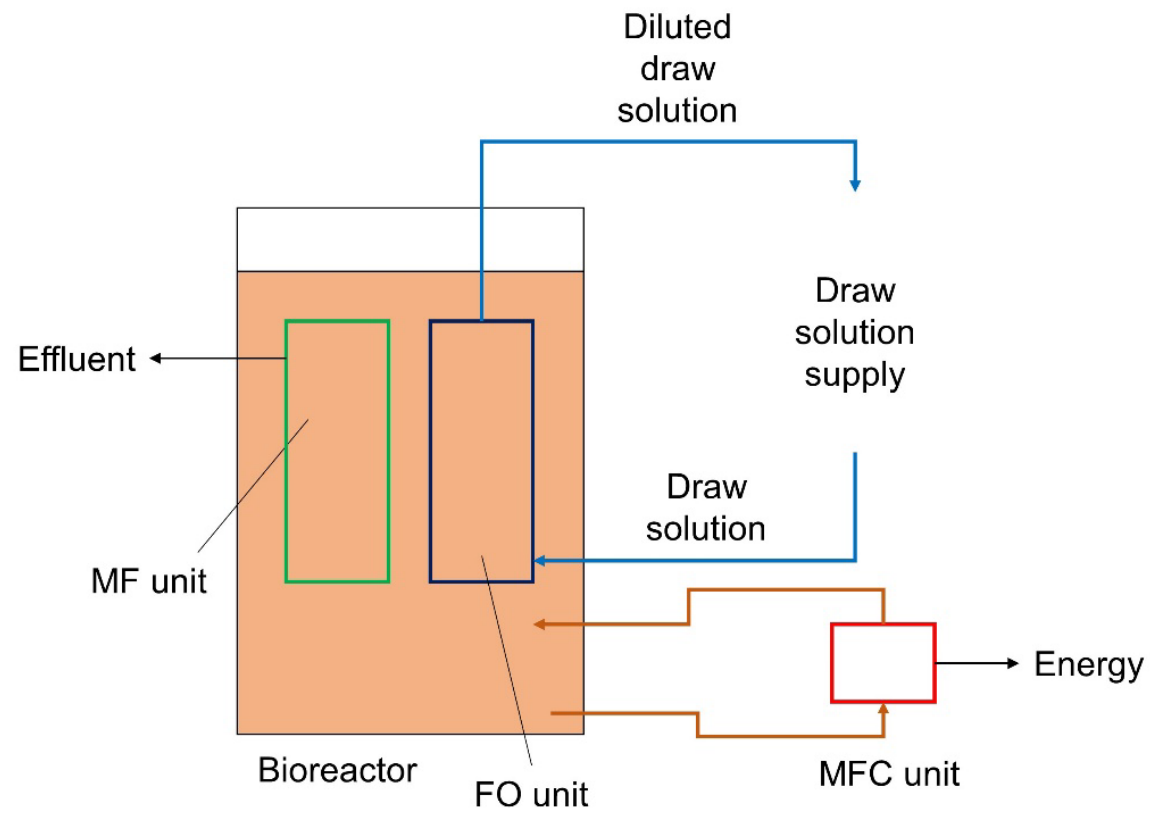

Fig. 6. Integrated OMBR-MFC for simultaneous wastewater treatment and bioenergy generation (adapted from [90]).

Other than energy recovery, integrated FO process is mostly associated with water recovery. However, unlike conventional pressurized membrane processes, the clean water is being recovered through another process during the regeneration of draw solution, where the FO process acts like a medium, extracting and transferring the clean water from feed to draw solutions. Plentiful of articles for water recovery through the regeneration of draw solution in integrated FO process have been reported, where the clean water can be extracted from various feed water (e.g. sewage, produced water, human urine, coal mine wastewater, etc.) and 
599

600

601

602

603

604

605

606

607

608

609

610

611

612

613

614

615

616

recovered from different draw solution regeneration technologies (mainly membrane-based such as NF, MD, and RO) [60-67,69]. Since the details of these integrated FO processes have already been discussed in the previous section, and regeneration of draw solution will be discussed in the following section, the readers are advised to refer to the cited references for further information on water recovery through integrated FO processes.

Apart from recovering the water and energy resources in wastewater sources, integrated FO process can also be employed for nutrients recovery. The FO process has the potential to enrich the ammonium and orthophosphate, which are the key constituents present in the digested sludge centrate for struvite precipitation [92]. The elevated concentration of ammonium and orthophosphate will enhance the product yield of struvite. Zou et al. (2017) incorporated FO with microbial electrolysis cells for the recovery of energy, nutrients, and water as shown in Fig. 7 [54]. The microbial electrolysis cells harvest the energy potential lies in the wastewater through its anode. On the other hand, FO process was responsible for the concentration of wastewater such that the phosphorus nutrient could be recovered easily through chemical precipitation. The water extracted from the wastewater would be recovered as clean water after the diluted draw solution was regenerated. This shows the versatility of FO as a concentration process in completing the recovery of energy-water-nutrient from wastewater.

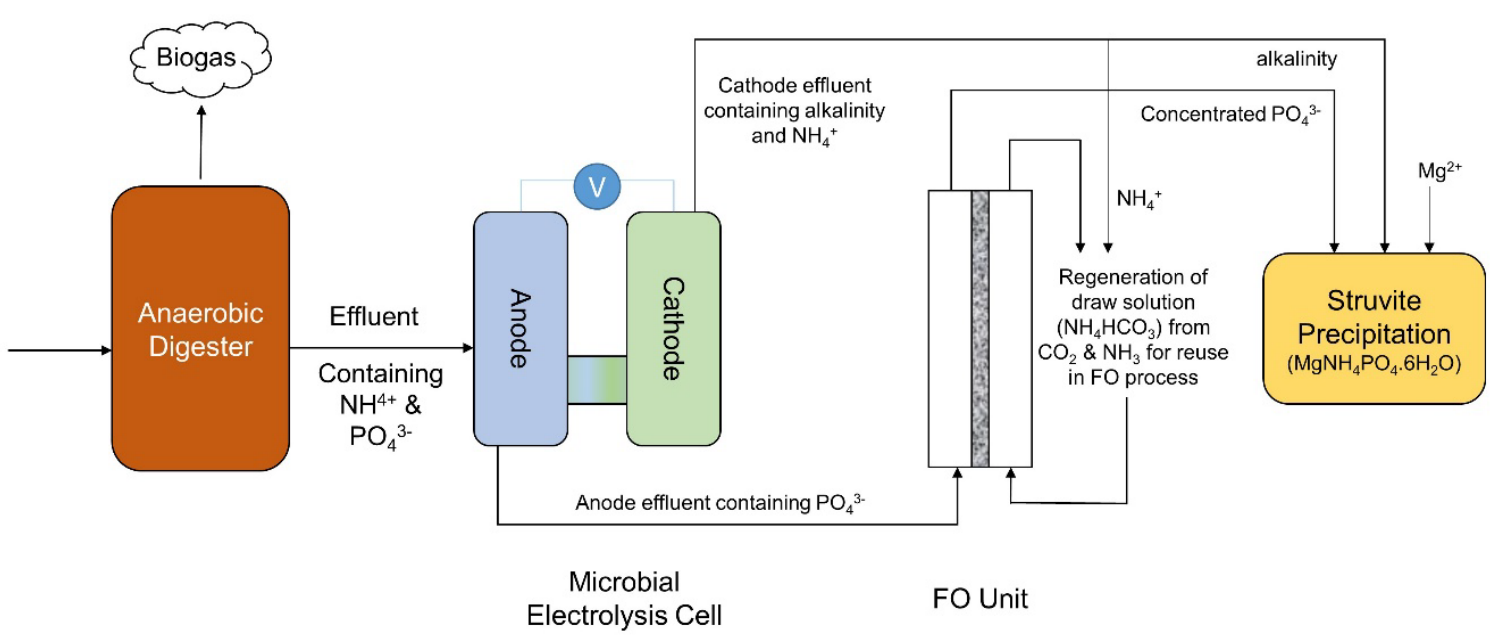


618

619

620

621

622

623

624

625

626

627

628

629

630

631

632

633

634

635

636

637

638

639

640

641

Fig. 7. Schematic idea of integrated MEC-FO system for nutrient-energy-water recovery (adapted from [54]).

\section{Regeneration of Draw Solution}

FO process will generate two streams, concentrated feed and diluted draw solutions, where the final product is determined by the purpose of having the concentration-dilution process. On one hand, the desired product will be the concentrated or diluted streams. On the other hand, the aim of the FO process is to extract and recover the clean water in the feed solution. As the product of a simple FO system is not pure water, but rather the water is trapped in the diluted draw solution, to obtain a pure water product FO needs to be part of an integrated process with a second step aimed at both re-concentrating the draw solution and producing a pure water product. The exception to this is in applications where the primary product is a concentrated feed and/or where the draw solute has been chosen where reconcentration is not required, such as seawater [93], fertiliser solutions which can be added to irrigation water [94-98], or lignosulfonate which can be applied to crop soils as a conditioner [99]. The majority of draw solution regeneration systems which have been investigated in the laboratory can be broadly divided into the categories of: pressure-driven filtration; thermally driven systems; magnetic recovery; electrolytic recovery; and precipitation based systems. Depending on the types of draw solution, FO process will be integrated with the corresponding draw solution regeneration process.

In cases where draw solution does not require regeneration, the associated costs consist merely of pumping, storage, and other assorted costs depending on the situation used. For the FO process itself, energy costs calculated by McGinnis and Elimelech was approximately 0.56 
$642 \mathrm{kWh} / \mathrm{m}^{3}$ for seawater desalination using an ammonia- $\mathrm{CO}_{2}$ based draw solute system, compared with an estimated $1.5 \mathrm{kWh} / \mathrm{m}^{3}$ minimum energy requirement for sweater $\mathrm{RO}[100,101]$.

644

$645 \quad$ Pressure-driven Filtration Processes

646 Membrane filtration processes, such as RO, NF, and UF have been investigated extensively for 647 the regeneration of diluted draw solutions. Whilst these systems are capable of treating a wide 648 range of feed waters directly, in this case the FO is being utilised as a low fouling primary 649 treatment, with the more fouling prone pressure-driven system being exposed to a relatively simple and low fouling draw solution [102,103]. For instance, a study of a hybrid FO-RO systems concluded that due to the relatively low water flux of the FO step, and consequent high specific energy costs when including the RO step, hybrid FO-RO systems are best applied when using feed waters with high fouling propensity [104]. When FO is applicable and monovalent salts are the chosen draw solutes, $\mathrm{RO}$ is an attractive recovery technology due its high salt rejection.

Yangali-Quintanilla et al. (2011) discovered that energy consumption for a hybrid FO-RO desalination process with a low-pressure RO step was half that of a conventional high-pressure RO process for the same feed water [14]. The authors cost analysis demonstrated that FO-RO systems are potentially more cost-effective than desalination using $\mathrm{RO}$ alone but only when high flux rates for the FO can be achieved (above $5.5 \mathrm{~L} / \mathrm{m}^{2} . \mathrm{h}$ ). This threshold was even higher when a low-pressure RO system with UF pre-treatment was the comparator $\left(10.5 \mathrm{~L} / \mathrm{m}^{2} . \mathrm{h}\right)$.

664 Cath et al. (2010) developed a process they termed osmotic dilution, which used a seawater draw solution to dewater wastewater [105]. The diluted seawater was then used as a feed for brackish RO, for clean water production. This allowed simultaneous dewatering of wastewater 
667

668

669

670

671

672

673

674

675

676

677

678

679

680

681

682

683

684

685

686

687

688

689

690

691

and seawater dilution. An estimated $63 \%$ of water was recovered from the wastewater source as a potable product, with the RO step being lower cost than desalinating seawater directly. Consequently, not only the RO process extracted water from the diluted seawater but also recovered the clean water that has been pulled from the wastewater through FO process.

NF and UF are attractive recovery steps due to their higher flux rates for a given pressure than $\mathrm{RO}$, but their higher molecular weight cut-offs make them unsuitable for recovery of draw solution consists of monovalent salts. Tan and $\mathrm{Ng}$ studied $\mathrm{NF}$ draw recovery process for $\mathrm{MgCl}_{2}$, $\mathrm{MgSO}_{4}, \mathrm{Na}_{2} \mathrm{SO}_{4}$ and ethanol [106]. They reported high flux rates potentially achievable for the combined $\left(10 \mathrm{~L} / \mathrm{m}^{2} . \mathrm{h}\right)$ and high rejection $(97.4 \%)$, with a double pass of NF needed to meet WHO standards for potable water. Other researchers desalinated brackish water using a hybrid FO-NF system with $\mathrm{NaSO}_{4}$ and $\mathrm{MgSO}_{4}$ as draw solutes [29]. They reported lower irreversible membrane fouling compared with conventional RO treatment of identical feedwater.

The high flux rates and low specific energy costs associated with UF make it an attractive second step when draw solutes are in the colloidal size range $[107,108]$. For instance, Ge et al. (2012) used UF to re-concentrate poly-acrylic acid (PAA) draw agent and achieved a rejection of 98.5 to $>99 \%$, depending on the molecular weight [109]. Nonetheless, this rejection rate still leads to a noticeable drop in FO flux after multiple cycles due to loss of solute and consequently lower draw solution osmotic potential. However, as was pointed out by Shaffer and co-workers, any good recovery step must necessarily make a return to the same original osmotic pressure and as such the minimum energy requirements are the same regardless of whether the second step is RO, NF or UF [30].

$\underline{\text { Temperature-driven systems }}$ 
692

693

694

695

696

697

698

699

700

701

702

703

704

705

706

707

708

709

710

711

712

713

714

715

716

The very first applications of FO used volatile draw solutes which allowed temperature based recovery to be used. Research has included decomposition into gases, such as when ammonium bicarbonate or sulfur dioxide are used [101,110-113]. Another technique which has been demonstrated was in the use of switchable polarity solvents. Stone et al. (2013) investigated this type of regeneration process using ternary mixtures of primary amines, $\mathrm{CO}_{2}$, and water [114]. The diluted draw solution was gently heated with application of oxygen or nitrogen gas, which caused the mixture to undergo a phase transition. Solid amines precipitates could then be easily removed, with remaining traces removed using RO. Further research found such a process combined with FO to be favorable, in terms of energy usage compared with conventional seawater RO [115]. Similar concept has also been demonstrated in a pilot-tested FO-membrane brine concentrator plant [116]. The draw solution used in this pilot plant was $\mathrm{NH}_{3} / \mathrm{CO}_{2}$ (a mixture of thermolytic ionic solutes) solution, where upon diluted would be directed to a distillation column to vaporize the draw solutes, which subsequently condensed to regain the draw solution for reuse. It was reported that the integrated system could attain water recovery of $64 \%$ from the produced water.

Membrane distillation (MD) is another thermally driven process which has been explored as a draw solution re-concentration process [92]. Yen et al. (2010) used an FO-MD hybrid process using de novo designed 2-methylimidazole based organic compounds as draw solutes, with the draw solution being continuously re-concentrated using MD [117]. They found that the flux rates were more stable over time due to the maintenance of the draw solution at a high concentration.

MD has also been combined with the use of temperature-sensitive polymers which undergo solubility changes at increased temperatures, combined with filtration of the precipitate (Fig. 
717

718

719

720

721

722

723

724

725

726

727

8) [118]. At the temperature above the low critical solution temperature of the draw solutes (heated before entering MD unit), it will agglomerate and lead to decreased osmotic pressure and thus higher water vapor pressure (subsequently enables the recovery of clean water). Thermo-responsive polymers have also been used to coat nanoparticle systems to allow redispersal of nanoparticle draw solutes which have been recovered using magnetic collection systems $[119,120]$.

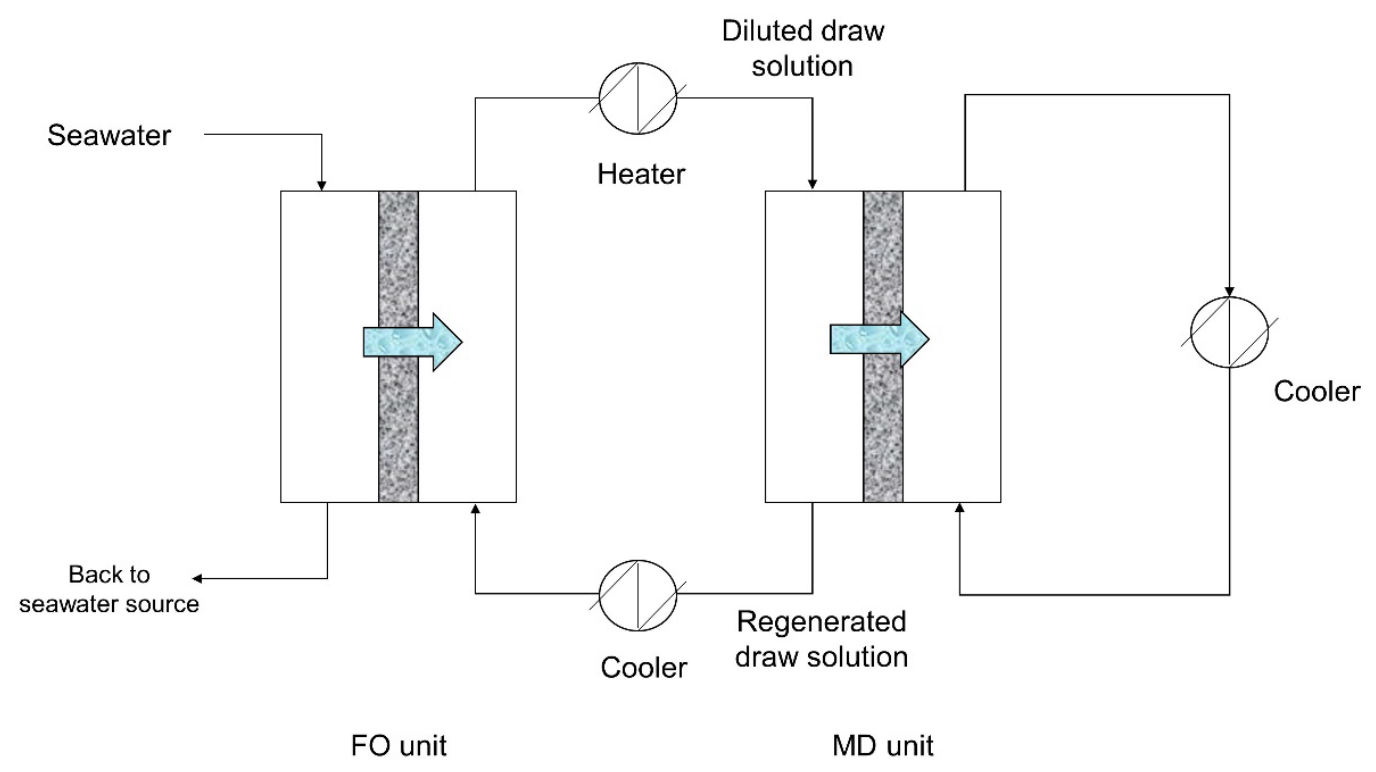

Fig. 8. Integrated FO-MD for seawater desalination and regeneration of draw solution (adapted from [118]).

The energy consumption of a hybrid FO-MD process for regenerating a thermos-responsive co-polymer draw solution system was investigated by Zhao et al. (2014) [118]. It was reported that $29 \mathrm{kWh} / \mathrm{m}^{3}$ was required, with the major contributor to the cost increase over pure FO being heating for the MD process. However, if a waste or free heat source is available this can be reduced considerably. For instance, Suwaileh et al. (2019) demonstrated that it is feasible to provide the heating for the MD process using solar collector systems, reducing the energy footprint for a hybrid FO-MD process to a significant extent [121]. 


\section{Magnetic Recovery}

Magnetic nanoparticles have been explored as potential draw agents in FO, which allows for the possibility of reconcentration using magnetic collectors. Typically, these have used magnetite nanoparticles coated with hydrophilic polymer brushes [122]. There are a number of issues with the magnetic recovery of nanoparticles, predominantly the aggregation of these particles, which ultimately leads to a loss in the osmotic potential of the nanoparticle suspensions and decreased FO flux after reconcentration cycles. Ling and Chung used ultrafiltration to separate magnetic nanoparticle agglomerates after particle collection, but with the reduction in magnetic properties of the particles [123]. Other researchers have used nanoparticles coated in environmentally responsive polymer brushes, to allow particle dispersion through application of external stimuli such as magnetic or sunlight $[120,124-126]$.

Razmjou et al. (2013) used thermally responsive hydrogels with entrapped magnetic nanoparticles. This allowed water to be released using magnetically induced heating, which was found to occur more evenly and at a greater rate than other forms of heating, releasing $53 \%$ of bound water using magnetism compared with 7\% from conventional heating [127].

Ling et al. (2011) studied UF for recovery of super-hydrophilic magnetic nanoparticle draw agents. It was reported that UF was a superior recovery method over the magnetic collection, due to lack of particle agglomeration and associated osmotic potential loss [124].

\section{Electrolytic Recovery}

Ling and Chung observed that magnetite nanoparticles had high electrical conductivity, and thus recovery using electrical fields is possible [125]. As shown in Fig. 9, particle accumulated on the anode placed in the draw solution tank allowing easy recovery, with metal ions left in 
760

761

762

763

764

765

766

767

768

769

770

771

772

773

solution recovered using NF. The alkaline metal ion solution was then used to re-disperse the nanoparticles. Water flux was maintained after repeated regeneration cycles. However, it is not clear what advantage such a system would have in terms of energy costs and after scale-up when compared with simple re-concentration of draw solution using NF alone, without the electrolysis step.

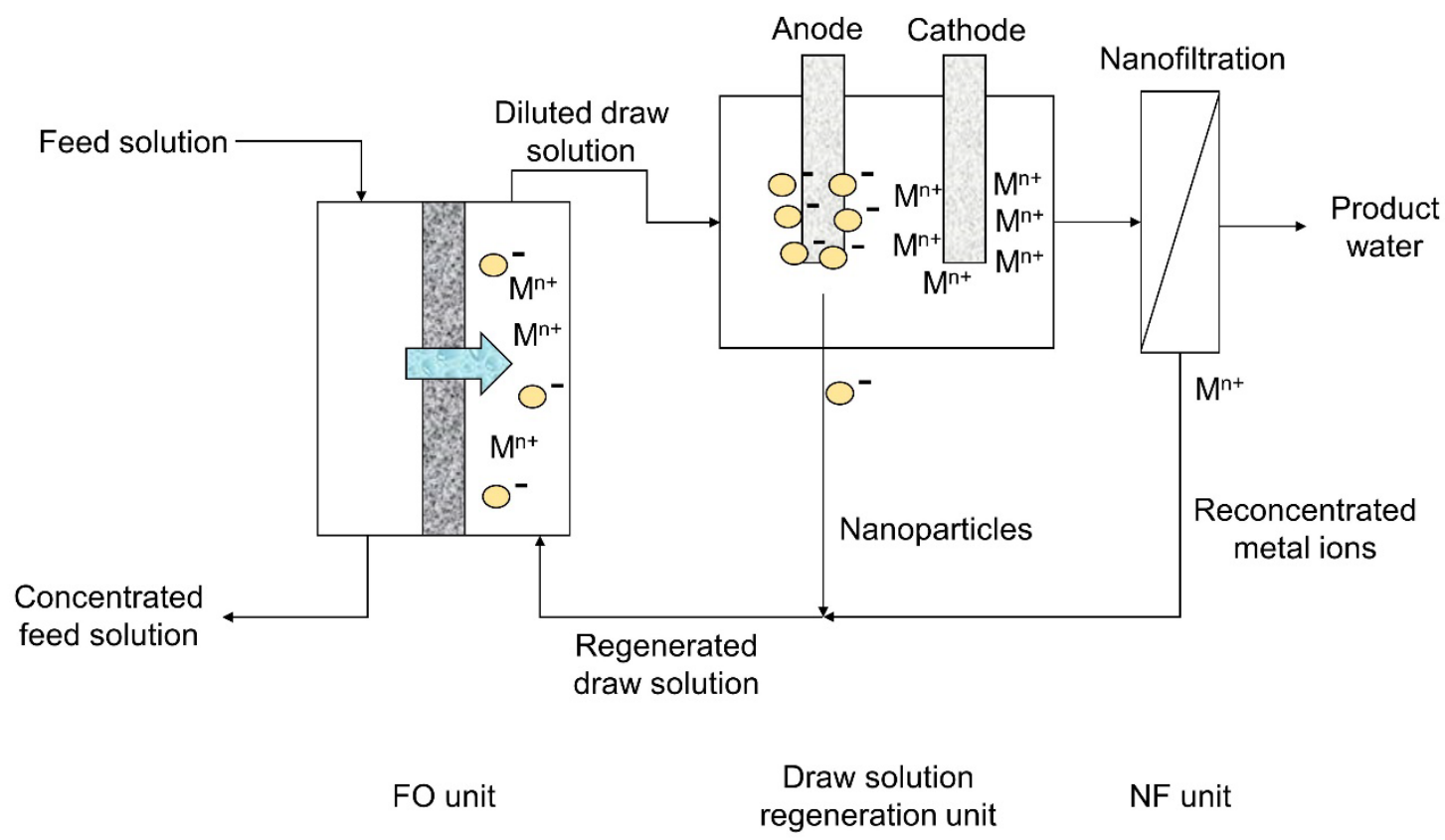

Fig. 9. Regeneration of draw solution via integrated electrical fields and NF membrane process (adapted from [125]).

Electrodialysis has also been investigated for the concentration of diammonium phosphate (DAP) draw solute which had leaked into the feed water during FO treatment of wastewater [128]. DAP recovery was reported to be $96.6 \%$, with the FO-ED system operating at 0.72 $\mathrm{kWh} / \mathrm{m}^{3}$ when using pure water feed. However, when using actual treated wastewater as a feed solution to the FO process intense fouling was observed, which required repeated cleaning steps.

\section{$\underline{\text { Precipitation of Draw Solute }}$}


777 Another method which has been explored to allow recovery and re-use of draw solutes is 778 through precipitating systems. For instance, an $\mathrm{Al}_{2}\left(\mathrm{SO}_{4}\right)_{3}$ draw solution has been used [34], 779 with the addition of calcium hydroxide causing the $\mathrm{Al}_{2}\left(\mathrm{SO}_{4}\right)_{3}$ to precipitate before recovery 780 either by sedimentation or filtration [129]. Other precipitating draw solutes, such as $\mathrm{MgSO}_{4}$ or $781 \mathrm{CuSO}_{4}$ have also been investigated using similar processes [130,131]. In the case of $\mathrm{CuSO}_{4}$, it was found that flux rates $\left(3.6 \mathrm{~L} / \mathrm{m}^{3} . \mathrm{h}\right)$ were obtained for brackish feed water, but osmotic pressures were not high enough to desalinate seawater. In addition, concentration polarization

784 effects were significant. However, precipitation of the $\mathrm{CuSO}_{4}$ using barium sulphate in a metathesis was capable of delivering pure water as a product without further polishing needed [130].

\section{FO Fouling Mitigation}

It has been generally reported that FO demonstrates a much lower fouling propensity and higher fouling reversibility than $\mathrm{RO}$, which could be attributed to the lack of applied hydraulic pressure $[103,132]$. These properties have enabled FO to be used for the handling of various low-quality water sources, including landfill leachate, municipal wastewater, leather industry effluent, coal mine wastewater, produced water, and anaerobic digestate $[39,48,57,60-67,133]$. However, fouling is still prevalent in the FO process as the phenomenon of flux decline can be frequently seen in the published results. Fouling in FO is normally associated with the deposition of suspended impurities on the membrane surface that block the passage of water and leads to concentration polarization [134]. Fouling will cripple the capability of the membrane process (flux and retention of impurities) and incur additional costs associated with cleaning for the restoration of membrane performance and membrane replacement expenses [135]. Hence, to alleviate the issue of membrane fouling, pretreatment processes can be 
801

802

803

804

805

806

807

808

809

810

811

812

813

814

815

816

817

818

819

820

821

822

823

824

825

integrated prior to the FO process, as what has been frequently practiced to minimize the fouling issues in other membrane processes.

The concentration of synthetic greywater using a hollow fiber thin-film composite FO membrane process demonstrated a substantial flux decline in the range $20-40 \%$, which could be attributed to the accumulation of protein on the membrane surface [136]. The formation of foulant layer on the membrane surface induced concentration polarization and increased the mass transfer resistance of water, which led to a decrease in the membrane flux. With the adoption of ferric flocculant prior to the FO process, the normalized flux decline was at a marginal $3 \%$ only, as compared to the flux decline without any pretreatment at about $40 \%$. Moreover, the recovery of the FO flux after the concentration of greywater was $100 \%$ where the foulant could be removed simply by soaking the membrane in deionized water. This signified the role of the flocculation process in removing some of the main contaminants $(96 \%$ of casein) in the synthetic greywater. Subsequently, the FO membrane was less exposed to the contaminants that could block its surface for water passage. A similar finding was also reported by Hawari et al. (2018) where the FO membrane flux was approximately 50\% higher when subjected to the concentration of pretreated dewatered construction water (through multimedia filtration) [137]. The significant increase in flux was due to the removal of large amounts of suspended solids and turbidity (impurities) by the multimedia filtration pretreatment process, reducing the turbidity and total suspended solids from 300 NTU and 325 ppm to 24 NTU and 21 ppm, respectively.

Fracking wastewater is highly saline water that contains different types of inorganic salts, dissolved organic compounds, oil, and sand [138]. It is high-strength wastewater that must be handled properly for the viability of the fracking industry, human health, and environment. 
Directly applying FO process to concentrate the fracking wastewater is not economically viable as the impurities will easily foul and damage the membrane. Hence, pretreatment is required to improve the integrity of FO process and its life expectancy by removing these compounds. Pretreatment with MF membrane has proved to be efficient in the removal of impurities present in fracking wastewater where it was reported the MF membrane removed nearly $52 \%$ of TOC and $98.5 \%$ of turbidity [139]. The pretreated fracking wastewater was then channeled to the FO process as feed solution. Comparison of FO flux patterns with raw and pretreated fracking wastewater showed that the latter achieved much lower flux decline $(14 \%)$ as compared to the former $(55 \%)$. This observation could be explained by the presence of MF pretreatment where a large portion of the foulants have been removed by MF. Similar trend of finding has also been reported where electrocoagulation was adopted as pretreatment to reduce up to $78 \%$ and $95 \%$ of TOC and turbidity in hydraulic fracturing produced water, respectively [140]. Without pretreatment, the FO membrane would be exposed to the impurities that have high potential to block the membrane surface.

Apart from chemical precipitation and physical filtration as the pretreatment processes, advanced oxidation process has also been integrated with FO for the treatment of anaerobically treated dairy effluent [141]. The advanced oxidation process is a technology that degrades the organic compounds present in the water sources [142]. The incorporation of an advanced oxidation process could help to eliminate the organic compounds in the wastewater and contribute to the alleviation of membrane fouling. For instance, Pramanik et al. (2019) incorporated ultraviolet and persulfate as pretreatment prior to the FO process for anaerobically treated dairy effluent [141]. The pretreatment process significantly reduced the concentration of biopolymers, humics, and other organics in the effluent, prompting the FO process to acquire higher water flux and water recovery. This could be attributed to the change in form of the 
851

852

853

854

855

856

857

compounds. Originally, these compounds possessed high molecular weight and were hydrophobic in nature, which meant that they had a high tendency to adhere to the membrane surface. The pretreatment process degraded the compounds from high to low molecular weight hydrophilic molecules, effectively minimizing the build-up of organic compounds on the FO membrane surface.

With the growing amount of municipal solid waste being disposed into landfills, the production of undesirable landfill leachate containing a range of persistent contaminants has also got more serious [143]. It has been reported that the FO membrane process could be employed to concentrate the landfill leachate though the process suffered from membrane fouling issues [144]. In a study conducted by Aftab et al. (2019), activated carbon (AC) and biochar (BC) have been integrated with FO process as pretreatment to alleviate the membrane fouling issues [133]. The addition of these adsorbents has resulted in enhancement in terms of flux, flux recovery, and membrane resistance, especially the experimental set with AC. These improvements could be due to the adsorptive property of AC that could capture the impurities in the leachate, which possessed the potential to foul and degrade the performance of FO membrane process. With the optimal dosage of $\mathrm{AC}$, the irreversible membrane resistance has been reduced to the level nearly equal to the virgin FO membrane (notable reduction in irreversible fouling). Hence, this shows that the removal of impurities in the water sources could help to alleviate the membrane fouling issues and enable the FO process to concentrate the feed water.

Mitigation and prevention of FO membrane fouling can also be achieved indirectly through the design of hybrid FO process. For instance, when the biological treatment process of OMBR has been modified into biofilm or entrapped cells forms, the fouling propensity of FO process 
has also been minimized $[48,49]$. When the bacteria grew in a fixed place (biofilm and polymeric matrix), the amount of free-form bacteria (suspended) in the bioreactor had also been reduced. Furthermore, the continuous draw-out of wastewater from the bioreactor helped to remove a portion of the dispersed cells. The change in the bioreactor form reduced the presence of suspended cells and subsequently minimizing the deposition of foulants on the FO membrane.

\section{Future Challenges}

Even though the potential of FO has been proven through integrated/hybrid processes, there are some areas of studies that need to be further investigated before the concept of integrated/hybrid FO process can be commercially implemented.

- Most of the performance data of integrated/hybrid FO process have been collected from lab-scale testing. There is still a lack of comprehensive data from pilot-scale or real application of integrated/hybrid FO process to convince the industry to adopt this concept in their process. Though pilot-tested results of FO in various wastewater treatment, for instance oil and gas wastewater, showed that the FO process could recover up to $85 \%$ of water for reuse, the case studies did not provide detailed information as in the overall cost of the whole treatment process (including draw solution regeneration) [145]. Furthermore, the flux decline appeared to be significant, which indicated the need of frequent cleaning $[6,68,146]$. Though it was claimed to be easily cleaned, the impacts of membrane fouling and cleaning on the overall performance and cost remain unexplored/unreported.

- Though the reported performance of integrated/hybrid FO processes are quite encouraging, the associated cost has often been left out with no data on the improvement of overall expenditure. For instance, pretreatment process installed prior to FO process can help to alleviate the membrane fouling issue, but benefits in term of cost benchmarking (expenses 
901 arising from the installation of pretreatment versus the gain from less frequent cleaning 902 and longer membrane lifespan) has never been properly documented.

903

- Feasibility of long-term operation of integrated/hybrid FO process has rarely been reported. As the FO membrane flux is considerably low, the question is whether the FO can produce sufficient flux to sustain the whole integrated/hybrid process for long-term continuous operation. This poses challenges to the membrane community in synthesizing FO membrane with great capability in terms of flux, retention of impurities, and long lifespan. Also, suitable low-cost draw solutes with ease of regeneration are vital for the long-term operation of integrated/hybrid FO process.

- Sustainability of the integrated/hybrid FO process should be benchmarked against the conventional or competitive alternative processes. As the world is aiming to achieve sustainable development, the insight of the associated environmental impacts with the implementation of integrated/hybrid FO process should be explored. This information may provide another side of the story on the attractiveness of integrated/hybrid FO process.

- The success of integrated/hybrid FO process is also highly relying on the quality of the FO membrane. Though remarkable advancement has been achieved in membrane fabrications, the commercial market still lacks of FO membranes that could support industrial scale application of FO process. Challenges remain in the aspect of control over membrane properties (such as thickness, porosity, pore structures, water permeability, selectivity, and antifouling) that will decide the practicality of up-scaled integrated/hybrid FO process in terms of productivity (flux) and membrane fouling. Incorporation of nanoparticles seem to be able to improve the membrane properties, yet it is challenged with the difficulties in term of leakage, cost, and mass production of the FO membrane incorporated with nanoparticles. 
- Another hindrance for widespread application of integrated/hybrid FO process is the availability of draw solute which can generate high osmotic pressure yet with minimum reverse solute flux and at the same time can be easily regenerated (minimal energy consumption). Though a significant amount of work has been done on the exploration of draw solute (type and regeneration) for FO process, the ideal draw solute for upscaling application remains absence. Existing draw solute is economic infeasible, either the material is costly or the cost associated with regeneration is too high.

Of all the challenges mentioned above, almost all are related to the economic aspect of FO process. The economic feasibility of integrated/hybrid FO process remains a disputed topic as comprehensive cost analysis for real application has been limited. Different views of economic feasibility have been reported in the literature, including the references discussed the previous sections. For instance, the FO process utilizing fertilizer as draw solution and operated at flowrate of $400 \mathrm{~mL} / \mathrm{min}$ consumed $0.396 \mathrm{kWh} / \mathrm{m}^{3}$ of energy, which was considered lower than the conventional activated sludge plant $\left(0.5647 \mathrm{kWh} / \mathrm{m}^{3}\right)$ and conventional MBR processes $\left(1.0465 \mathrm{kWh} / \mathrm{m}^{3}\right)[147-150]$. However, the finding was limited to lab-scale testing using low salinity brackish water $(5000 \mathrm{ppm} \mathrm{NaCl})$ and without the need of draw solution regeneration, where the relative size of an actual plant receiving real sample might give a different performance in the long run. Furthermore, the concentration polarization issue was apparent in the testing, as reflected by the FO flux decline. This indicates the possibility of higher expenditure for long time operation in real application.

The increasingly popular integrated/hybrid FO-MBR process for wastewater reclamation though possesses attractive performance, economic analysis revealed the opposite finding. Based on the SEC calculated, the integrated FO-MBR recorded up to seven times higher value 
950 than that for classical RO process $\left(0.29-1.2 \mathrm{kWh} / \mathrm{m}^{3}\right)[6,151]$. In another pilot-scale 951 demonstration plant, the integrated FO-NF process was treating MBR effluent for water recovery. The NF process was used to regenerate the draw solution while extracting clean water.

953 The cost of product water was approximately $0.96 € / \mathrm{m}^{3}$, which was twice the cost for 954 desalination (UF-RO) as tertiary treatment [64]. The much higher cost could be attributed to the loss of draw solute (NF permeate and reverse solute flux) and energy consumption for the NF process. Nonetheless, it was argued that the cost of a large-scale integrated FO-NF process might be competitive as the typical UF-RO process for tertiary wastewater reclamation.

Despite there are positive simulation results supporting the economic feasibility of FO process for integrated desalination process, there is no evidence from large-scale demonstrations that integrated FO-RO process can consume less energy than the classical seawater RO desalination process. Instead, it has been determined that integrated FO-RO can only energetically compete with the RO desalination process at flux above $30 \mathrm{~L} / \mathrm{m}^{3} . \mathrm{h}$ or associated recovery of more than $50 \%[6,152]$. However, the integrated FO-RO desalination process could possibly attain savings in energy if it was using secondary wastewater effluent as feed solution to dilute the seawater (draw solution), as discussed in the previous section [14,16]. Alternatively, the cost of the integrated FO process could be potentially reduced if the regeneration of draw solution is not required, or the energy required could be derived from low-cost or renewable sources such as solar energy or waste heat $[118,121,150]$.

\section{Conclusions and Perspectives}

972 In general, the possibility of integrating and hybridizing FO membrane with other processes enables the full utilization of FO capability in various applications. To sum up, integrated/hybrid FO membrane processes have brought the following benefits: 
- Dilution of seawater or brine minimizes the scaling issue in seawater RO desalination and MSF desalination processes and potentially reduces the energy consumption due to lower osmotic pressure of diluted seawater or brine.

- Enhancement of the quality of extracted water from MBR by preventing the impurities from passing through to the draw solution side. The dewatering capability of FO helps to maintain the characteristics of the wastewater in the bioreactor, making the conditions suitable for optimal bacterial activity in degrading the organic impurities and producing biogas (methane) as renewable energy.

- The modification on the bacterial growth mode in the bioreactor from suspended cells form to attached growth (biofilm) or entrapped-cell form mitigates the organic fouling of FO membrane in OMBR.

- Integration with other technologies such as coagulation, membrane, adsorption, and electrochemical processes removes the total organic carbon and total suspended solids in the wastewater. This helps to minimize the fouling propensity of FO membrane in wastewater treatment process since these compounds could easily block and clog the membrane.

- Integrated FO process could be an alternative concentration process for food and beverage industries where the bioactive compounds are especially sensitive and vulnerable to heat. The integrated FO process also converts the waste stream into valuable materials by concentrating the valuable and useful compounds in the solution, or preparing the solution suitable for subsequent downstream process.

- Concentrating the wastewater in electrochemical processes for more efficient energy generation from microorganism and the recovery of phosphorus nutrient. 
1004

1005

1006

1007

1008

1009

1010

1011

1012

1013

1014

1015

1016

1017

1018

1019

1020

- Regeneration of draw solution through various approaches (pressure-driven filtration, temperature-driven, magnetic recovery, electrolytic recovery, and precipitation) provides the FO an opportunity to be operated continuously and be applied in many applications.

- Installing pretreatment processes prior to FO helps to mitigate the fouling issues associated with FO process. This ensures the FO process can be operated without severe flux decline and the membrane can be used for a longer period on top of less frequent of cleaning need.

Research on forward osmosis (FO) is attracting increasing interest due to its unique ability to provide an alternative mechanism to the other membrane processes especially for concentrating or diluting a solution using membranes. However, it is important that FO processes are integrated with other technologies in order to provide better process performance and cost saving. Various combinations of FO with other techniques have been reported especially for the purpose of process enhancement, draw solution regeneration, and pretreatment for FO fouling mitigation. These combinations have been shown to provide advantages in terms of reducing the membrane fouling propensity; preparing the solution suitable for subsequent value-added uses and production of renewable energy; lowering the costs associated with energy consumption; enhancing the quality of treated water; and enabling the continuous operation of FO through the regeneration of draw solution. There are many areas that still can be explored within these applications especially in terms of process optimization, large scale performance, economic assessment, and sustainable operations. The future challenges will be dependent on how FO can be hybridized or integrated in combination with other technologies to minimize its own shortcoming while enhancing the overall performance.

\section{Acknowledgement}

The authors would like to thank the Royal Society for funding this work through Royal Society International Collaboration Award (IC160133) (acknowledged under the grant code KK-2017006 at Universiti Kebangsaan Malaysia). 
Reference

[1] W.L. Ang, A.W. Mohammad, N. Hilal, C.P. Leo, A review on the applicability of integrated/hybrid membrane processes in water treatment and desalination plants, Desalination. 363 (2014) 2-18. http://dx.doi.org/10.1016/j.desal.2014.03.008.

[2] C. Bhattacharjee, V.K. Saxena, S. Dutta, Fruit juice processing using membrane technology: A review, Innov. Food Sci. Emerg. Technol. 43 (2017) 136-153. doi:10.1016/j.ifset.2017.08.002.

[3] C.M. Chew, M.K. Aroua, M.A. Hussain, W.M.Z.W. Ismail, Practical performance analysis of an industrial-scale ultrafiltration membrane water treatment plant, J. Taiwan Inst. Chem. Eng. 46 (2015) 132-139. doi:10.1016/j.jtice.2014.09.013.

[4] M. Padaki, R. Surya Murali, M.S. Abdullah, N. Misdan, A. Moslehyani, M.A. Kassim, N. Hilal, A.F. Ismail, Membrane technology enhancement in oil-water separation. A review, Desalination. 357 (2015) 197-207. doi:10.1016/j.desal.2014.11.023.

[5] G. Gopi, G. Arthanareeswaran, I. AF, Perspective of renewable desalination by using membrane distillation, Chem. Eng. Res. Des. 144 (2019) 520-537. doi:10.1016/j.cherd.2019.02.036.

[6] A.M. Awad, R. Jalab, J. Minier-Matar, S. Adham, M.S. Nasser, S.J. Judd, The status of forward osmosis technology implementation, Desalination. 461 (2019) 10-21. doi:10.1016/j.desal.2019.03.013.

[7] L. Chekli, S. Phuntsho, J.E. Kim, J. Kim, J.Y. Choi, J.S. Choi, S. Kim, J.H. Kim, S. Hong, J. Sohn, H.K. Shon, A comprehensive review of hybrid forward osmosis systems: Performance, applications and future prospects, J. Memb. Sci. 497 (2016) 430-449. doi:10.1016/j.memsci.2015.09.041.

[8] Y. Kim, M. Elimelech, H.K. Shon, S. Hong, Combined organic and colloidal fouling in forward osmosis: Fouling reversibility and the role of applied pressure, J. Memb. Sci. 460 (2014) 206-212. doi:10.1016/j.memsci.2014.02.038.

[9] Y.N. Wang, K. Goh, X. Li, L. Setiawan, R. Wang, Membranes and processes for forward osmosis-based desalination: Recent advances and future prospects, Desalination. 434 (2018) 81-99. doi:10.1016/j.desal.2017.10.028.

[10] D.J. Johnson, W.A. Suwaileh, A.W. Mohammed, N. Hilal, Osmotic's potential: An overview of draw solutes for forward osmosis, Desalination. 434 (2018) 100-120. doi:10.1016/j.desal.2017.09.017.

[11] W.L. Ang, A. Wahab Mohammad, D. Johnson, N. Hilal, Forward osmosis research trends in desalination and wastewater treatment: A review of research trends over the past decade, J. Water Process Eng. 31 (2019) 100886. doi:10.1016/j.jwpe.2019.100886.

[12] W.L. Ang, A.W. Mohammad, Integrated and hybrid process technology, Elsevier Inc., 2019. doi:10.1016/b978-0-12-816170-8.00009-0.

[13] M. Qasim, M. Badrelzaman, N.N. Darwish, N.A. Darwish, N. Hilal, Reverse osmosis desalination: A state-of-the-art review, Desalination. 459 (2019) 59-104. doi:10.1016/j.desal.2019.02.008.

[14] V. Yangali-quintanilla, Z. Li, R. Valladares, Q. Li, G. Amy, Indirect desalination of Red Sea water with forward osmosis and low pressure reverse osmosis for water reuse, Desalination. 280 (2011) 160-166. doi:10.1016/j.desal.2011.06.066.

[15] J. Seo, Y. Mi, S. Ho, S. Ji, H. Park, J. Ha, An optimization strategy for a forward osmosis-reverse osmosis hybrid process for wastewater reuse and seawater desalination : A modeling study, Desalination. 463 (2019) 40-49. doi:10.1016/j.desal.2019.03.012.

[16] V.S.T. Sim, Q. She, T.H. Chong, C.Y. Tang, A.G. Fane, W.B. Krantz, Strategic CoLocation in a Hybrid Process Involving Desalination and Pressure Retarded Osmosis 
(PRO), Membranes (Basel). 3 (2013) 98-125. doi:10.3390/membranes3030098.

[17] B.G. Choi, M. Zhan, K. Shin, S. Lee, S. Hong, Pilot-scale evaluation of FO-RO osmotic dilution process for treating wastewater from coal-fired power plant integrated with seawater desalination, J. Memb. Sci. 540 (2017) 78-87. doi:10.1016/j.memsci.2017.06.036.

[18] C.F. Wan, T.S. Chung, Techno-economic evaluation of various RO+PRO and RO+FO integrated processes, Appl. Energy. 212 (2018) 1038-1050. doi:10.1016/j.apenergy.2017.12.124.

[19] G. Blandin, A.R.D. Verliefde, C.Y. Tang, P. Le-clech, Opportunities to reach economic sustainability in forward osmosis - reverse osmosis hybrids for seawater desalination, Desalination. 363 (2015) 26-36. doi:10.1016/j.desal.2014.12.011.

[20] J.E. Kim, S. Phuntsho, S.M. Ali, J.Y. Choi, H.K. Shon, Forward osmosis membrane modular configurations for osmotic dilution of seawater by forward osmosis and reverse osmosis hybrid system, Water Res. 128 (2018) 183-192. doi:10.1016/j.watres.2017.10.042.

[21] S. Kook, C. Lee, T. Tin, J. Lee, H. Kyong, I.S. Kim, Serially connected forward osmosis membrane elements of pressure-assisted forward osmosis-reverse osmosis hybrid system : Process performance and economic analysis, Desalination. 448 (2018) 1-12. doi:10.1016/j.desal.2018.09.019.

[22] R. Valladares Linares, Z. Li, V. Yangali-Quintanilla, N. Ghaffour, G. Amy, T. Leiknes, J.S. Vrouwenvelder, Life cycle cost of a hybrid forward osmosis - low pressure reverse osmosis system for seawater desalination and wastewater recovery, Water Res. 88 (2016) 225-234. doi:10.1016/j.watres.2015.10.017.

[23] N.A. Thompson, P.G. Nicoll, Forward osmosis desalination: a commercial reality, IDA World Congr. - Perth Conv. Exhib. Cent. (PCEC), Perth, West. Aust. Sept. 4-9, 2011. (2011) 16. http://www.modernwater.co.uk/oldsite/assets/pdfs/PERTH Sept11 FO Desal A Commercial Reality.pdf.

[24] M.S. Thabit, A.H. Hawari, M. Hafez, S. Zaidi, G. Zaragoza, A. Altaee, Evaluation of forward osmosis as a pretreatment process for multi stage fl ash seawater desalination, Desalination. 461 (2019) 22-29. doi:10.1016/j.desal.2019.03.015.

[25] A. Taee, A. Mabrouk, K. Bourouni, A novel Forward osmosis membrane pretreatment of seawater for thermal desalination processes, Desalination. 326 (2013) 19-29. doi:10.1016/j.desal.2013.07.008.

[26] A. Altaee, N. Hilal, High recovery rate NF - FO - RO hybrid system for inland brackish water treatment, Desalination. 363 (2015) 19-25. doi:10.1016/j.desal.2014.12.017.

[27] Y. Zhang, L. Pinoy, B. Meesschaert, B. Van Der Bruggen, A Natural Driven Membrane Process for Brackish and Wastewater Treatment: Photovoltaic Powered ED and FO Hybrid System, Environ. Sci. Technol. 47 (2013) 10548-10555.

[28] T.N. Bitaw, K. Park, D.R. Yang, Optimization on a new hybrid Forward osmosisElectrodialysis-Reverse osmosis seawater desalination process, Desalination. 398 (2016) 265-281. doi:10.1016/j.desal.2016.07.032.

[29] S. Zhao, L. Zou, D. Mulcahy, Brackish water desalination by a hybrid forward osmosis - nano fi ltration system using divalent draw solute, Desalination. 284 (2012) 175181. doi:10.1016/j.desal.2011.08.053.

[30] D.L. Shaffer, J.R. Werber, H. Jaramillo, S. Lin, M. Elimelech, Forward osmosis : Where are we now ?, Desalination. 356 (2015) 271-284. doi:10.1016/j.desal.2014.10.031.

[31] E. Tilley, L. Ulrich, C. Luthi, P. Reymond, C. Zurbrugg, Compendium of Sanitation Systems and Technologies, 2014. http://www.iwa-network.org/wp- 
content/uploads/2016/06/Compendium-Sanitation-Systems-and-Technologies.pdf.

[32] X. Zheng, Z. Zhang, D. Yu, X. Chen, R. Cheng, S. Min, J. Wang, Q. Xiao, J. Wang, Overview of membrane technology applications for industrial wastewater treatment in China to increase water supply, Resour. Conserv. Recycl. 105 (2015) 1-10. doi:10.1016/j.resconrec.2015.09.012.

[33] L.D. Nghiem, T. Fujioka, Removal of Emerging Contaminants for Water Reuse by Membrane Technology, Elsevier B.V., 2016. doi:10.1016/B978-0-444-63312-5.000097.

[34] J. Arévalo, G. Garralón, F. Plaza, B. Moreno, J. Pérez, M.Á. Gómez, Wastewater reuse after treatment by tertiary ultrafiltration and a membrane bioreactor (MBR): a comparative study, Desalination. 243 (2009) 32-41. doi:10.1016/j.desal.2008.04.013.

[35] J. Ottoson, A. Hansen, B. Björlenius, H. Norder, T.A. Stenström, Removal of viruses, parasitic protozoa and microbial indicators in conventional and membrane processes in a wastewater pilot plant, Water Res. 40 (2006) 1449-1457. doi:10.1016/j.watres.2006.01.039.

[36] G. Blandin, C. Gautier, M.S. Toran, H. Monclus, I. Rodriguez-roda, J. Comas, Retrofitting membrane bioreactor (MBR) into osmotic membrane bioreactor ( OMBR ): a pilot scale study, Chem. Eng. J. (2018). doi:10.1016/j.cej.2018.01.103.

[37] N. Cong, H. Thi, S. Chen, H. Hao, W. Guo, W. Hao, S. Sinha, C. Li, H. Hsu, A novel osmosis membrane bioreactor-membrane distillation hybrid system for wastewater treatment and reuse, Bioresour. Technol. 209 (2016) 8-15. doi:10.1016/j.biortech.2016.02.102.

[38] X. Wang, V.W.C. Chang, C.Y. Tang, Osmotic membrane bioreactor (OMBR) technology for wastewater treatment and reclamation: Advances, challenges, and prospects for the future, J. Memb. Sci. 504 (2016) 113-132. doi:10.1016/j.memsci.2016.01.010.

[39] J. Zhao, Y. Li, S. Pan, Q. Tu, H. Zhu, Performance of a forward osmotic membrane bioreactor for anaerobic digestion of waste sludge with increasing solid concentration, J. Environ. Man. 246 (2019) 239-246.

[40] Y. Gao, Z. Fang, P. Liang, X. Zhang, Y. Qiu, K. Kimura, X. Huang, Anaerobic digestion performance of concentrated municipal sewage by forward osmosis membrane : Focus on the impact of salt and ammonia nitrogen, Bioresour. Technol. 276 (2019) 204-210. doi:10.1016/j.biortech.2019.01.016.

[41] B. Kumar, F.I. Hai, A.J. Ansari, F.A. Roddick, Mining phosphorus from anaerobically treated dairy manure by forward osmosis membrane, J. Ind. Eng. Chem. 78 (2019) 425-432.

[42] W.C.L. Lay, Y. Liu, A.G. Fane, Impacts of salinity on the performance of high retention membrane bioreactors for water reclamation: A review, Water Res. 44 (2010) 21-40. doi:10.1016/j.watres.2009.09.026.

[43] P.B. Moser, C. Bretas, E. Coutinho, C. Faria, B.C. Ricci, A. Cláudia, F.P. Cerqueira, M.C.S. Amaral, Comparison of hybrid ultrafiltration-osmotic membrane bioreactor and conventional membrane bioreactor for oil refinery effluent treatment, Chem. Eng. J. 378 (2019) 121952.

[44] W. Zhu, X. Wang, Q. She, X. Li, Y. Ren, Osmotic membrane bioreactors assisted with microfiltration membrane for salinity control (MF-OMBR) operating at high sludge concentrations: performance and implications, Chem. Eng. J. (2017). doi:10.1016/j.cej.2017.12.148.

[45] X. Wang, C. Wang, C.Y. Tang, T. Hu, X. Li, Y. Ren, Development of a novel anaerobic membrane bioreactor simultaneously integrating microfiltration and forward osmosis membranes for low-strength wastewater treatment, J. Memb. Sci. 527 (2017) 
1-7.

[46] W. Luo, F.I. Hai, W.E. Price, W. Guo, H.H. Ngo, K. Yamamoto, L.D. Nghiem, Phosphorus and water recovery by a novel osmotic membrane bioreactor - reverse osmosis system, Bioresour. Technol. 200 (2016) 297-304.

[47] R.W. Holloway, A.S. Wait, A. Fernandes da Silva, J. Herron, M.D. Schutter, K. Lampi, T.Y. Cath, Long-term pilot scale investigation of novel hybrid ultrafiltrationosmotic membrane bioreactors, Desalination. 363 (2015) 64-74. doi:10.1016/j.desal.2014.05.040.

[48] G. Qiu, S. Zhang, D. Shankari, S. Raghavan, S. Das, Y. Ting, The potential of hybrid forward osmosis membrane bioreactor ( FOMBR ) processes in achieving high throughput treatment of municipal wastewater with enhanced phosphorus recovery, Water Res. 105 (2016) 370-382.

[49] C. Juntawang, C. Rongsayamanont, E. Khan, Entrapped-cells-based anaerobic forward osmosis membrane bioreactor treating medium-strength domestic wastewater: Fouling characterization and performance evaluation, Chemosphere. 225 (2019) 226-237. doi:10.1016/j.chemosphere.2019.03.032.

[50] W.J. Yap, J. Zhang, W.C.L. Lay, B. Cao, A.G. Fane, Y. Liu, State of the art of osmotic membrane bioreactors for water reclamation, Bioresour. Technol. 122 (2012) 217-222. doi:10.1016/j.biortech.2012.03.060.

[51] G. Qiu, Y.P. Ting, Short-term fouling propensity and flux behavior in an osmotic membrane bioreactor for wastewater treatment, Desalination. 332 (2014) 91-99. doi:10.1016/j.desal.2013.11.010.

[52] B.D. Coday, P. Xu, E.G. Beaudry, J. Herron, K. Lampi, N.T. Hancock, T.Y. Cath, The sweet spot of forward osmosis : Treatment of produced water, drilling wastewater, and other complex and dif fi cult liquid streams, Desalination. 333 (2014) 23-35. doi:10.1016/j.desal.2013.11.014.

[53] P. Liu, H. Zhang, Y. Feng, C. Shen, F. Yang, Integrating electrochemical oxidation into forward osmosis process for removal of trace antibiotics in wastewater, J. Hazard. Mater. 296 (2015) 248-255. doi:10.1016/j.jhazmat.2015.04.048.

[54] S. Zou, M. Qin, Y. Moreau, Z. He, Nutrient-energy-water recovery from synthetic sidestream centrate using a microbial electrolysis cell - forward osmosis hybrid system, J. Clean. Prod. 154 (2017) 16-25. doi:10.1016/j.jclepro.2017.03.199.

[55] D. Lu, Q. Liu, Y. Zhao, H. Liu, J. Ma, Treatment and energy utilization of oily water via integrated ultra fi ltration- forward osmosis - membrane distillation ( UF-FO-MD ) system, J. Memb. Sci. 548 (2018) 275-287. doi:10.1016/j.memsci.2017.11.004.

[56] B. Aftab, Y. Sik, J. Cho, J. Hur, Targeted removal of organic foulants in land fill leachate in forward osmosis system integrated with biochar/activated carbon treatment, Water Res. 160 (2019) 217-227.

[57] K. Sardari, P. Fyfe, S.R. Wickramasinghe, Integrated electrocoagulation - Forward osmosis - Membrane distillation for sustainable water recovery from hydraulic fracturing produced water, J. Memb. Sci. 574 (2019) 325-337.

[58] S. Islam, K. Touati, S. Rahaman, Feasibility of a hybrid membrane-based process ( MF-FO-MD ) for fracking wastewater treatment, Sep. Purif. Technol. 229 (2019) 115802.

[59] E.A. Bell, T.E. Poynor, K.B. Newhart, J. Regnery, B.D. Coday, T.Y. Cath, Produced water treatment using forward osmosis membranes: Evaluation of extended-time performance and fouling, J. Memb. Sci. 525 (2017) 77-88. doi:10.1016/j.memsci.2016.10.032.

[60] P. Pal, M. Sardar, M. Pal, S. Chakrabortty, J. Nayak, Modelling forward osmosisnanofiltration integrated process for treatment and recirculation of leather industry 
wastewater, Comput. Chem. Eng. 127 (2019) 99-110.

[61] S. Lee, Y. Kim, S. Hong, Treatment of industrial wastewater produced by desulfurization process in a coal-fired power plant via FO-MD hybrid process, Chemosphere. 210 (2018) 44-51. doi:10.1016/j.chemosphere.2018.06.180.

[62] N.C. Nguyen, H.T. Nguyen, S.T. Ho, S.S. Chen, H.H. Ngo, W. Guo, S.S. Ray, H. Te Hsu, Exploring high charge of phosphate as new draw solute in a forward osmosismembrane distillation hybrid system for concentrating high-nutrient sludge, Sci. Total Environ. 557-558 (2016) 44-50. doi:10.1016/j.scitotenv.2016.03.025.

[63] R. Thiruvenkatachari, M. Francis, M. Cunnington, S. Su, Application of integrated forward and reverse osmosis for coal mine wastewater desalination, Sep. Purif. Technol. 163 (2016) 181-188. doi:10.1016/j.seppur.2016.02.034.

[64] B. Corzo, T. de la Torre, C. Sans, R. Escorihuela, S. Navea, J.J. Malfeito, Long-term evaluation of a forward osmosis-nanofiltration demonstration plant for wastewater reuse in agriculture, Chem. Eng. J. 338 (2018) 383-391.

doi:10.1016/j.cej.2018.01.042.

[65] B.C. Ricci, B. Skibinski, K. Koch, C. Mancel, C.Q. Celestino, I.L.C. Cunha, M.R. Silva, C.B. Alvim, C. V Faria, L.H. Andrade, L.C. Lange, M.C.S. Amaral, Critical performance assessment of a submerged hybrid forward osmosis-membrane distillation system, Desalination. 468 (2019) 114082.

[66] R.A. Maltos, J. Regnery, N. Almaraz, S. Fox, M. Schutter, T.J. Cath, M. Veres, B.D. Coday, T.Y. Cath, Produced water impact on membrane integrity during extended pilot testing of forward osmosis - reverse osmosis treatment, Desalination. (2018) 0-1. doi:10.1016/j.desal.2018.02.029.

[67] Q. Liu, C. Liu, L. Zhao, W. Ma, H. Liu, J. Ma, Integrated Forward OsmosisMembrane Distillation Process for Human Urine Treatment, Water Res. 91 (2016) 4554. doi:10.1016/j.watres.2015.12.045.

[68] S. Phuntsho, J.E. Kim, M.A.H. Johir, S. Hong, Z. Li, N. Ghaffour, T.O. Leiknes, H.K. Shon, Fertiliser drawn forward osmosis process: Pilot-scale desalination of mine impaired water for fertigation, J. Memb. Sci. 508 (2016) 22-31. doi:10.1016/j.memsci.2016.02.024.

[69] M. Xie, L.D. Nghiem, W.E. Price, M. Elimelech, A forward osmosis-membrane distillation hybrid process for direct sewer mining: System performance and limitations, Environ. Sci. Technol. 47 (2013) 13486-13493. doi:10.1021/es404056e.

[70] L. Chekli, J.E. Kim, I. El Saliby, Y. Kim, S. Phuntsho, S. Li, N. Ghaffour, T.O. Leiknes, H. Kyong Shon, Fertilizer drawn forward osmosis process for sustainable water reuse to grow hydroponic lettuce using commercial nutrient solution, Sep. Purif. Technol. 181 (2017) 18-28. doi:10.1016/j.seppur.2017.03.008.

[71] P. Onsekizoglu, K.S. Bahceci, M.J. Acar, Clarification and the concentration of apple juice using membrane processes: A comparative quality assessment, J. Memb. Sci. 352 (2010) 160-165. doi:10.1016/j.memsci.2010.02.004.

[72] D. Mondal, S.K. Nataraj, A.V. Rami Reddy, K.K. Ghara, P. Maiti, S.C. Upadhyay, P.K. Ghosh, Four-fold concentration of sucrose in sugarcane juice through energy efficient forward osmosis using sea bittern as draw solution, RSC Adv. 5 (2015) 17872-17878. doi:10.1039/c5ra00617a.

[73] S. Gunko, S. Verbych, M. Bryk, N. Hilal, Concentration of apple juice using direct contact membrane distillation, Desalination. 190 (2006) 117-124. doi:10.1016/j.desal.2005.09.001.

[74] X. An, Y. Hu, N. Wang, Z. Zhou, Z. Liu, Continuous juice concentration by integrating forward osmosis with membrane distillation using potassium sorbate preservative as a draw solute, J. Memb. Sci. 573 (2019) 192-199. 
doi:10.1016/j.memsci.2018.12.010.

[75] N.K. Rastogi, Reverse Osmosis and Forward Osmosis for the Concentration of Fruit Juices, Elsevier Inc., 2017. doi:10.1016/B978-0-12-802230-6.00013-8.

[76] P. Menchik, C.I. Moraru, Nonthermal concentration of liquid foods by a combination of reverse osmosis and forward osmosis . Acid whey: A case study, J. Food Eng. 253 (2019) 40-48. doi:10.1016/j.jfoodeng.2019.02.015.

[77] C. Aydiner, U. Sen, S. Topcu, D. Sesli, D. Ekinci, A.D. Altinay, B. Ozbey, D.Y. Koseoglu-Imer, B. Keskinler, Techno-economic investigation of water recovery and whey powder production from whey using UF/RO and FO/RO integrated membrane systems, Desalin. Water Treat. 52 (2014) 123-133. doi:10.1080/19443994.2013.786655.

[78] C. Aydiner, U. Sen, S. Topcu, D. Ekinci, A.D. Altinay, D.Y. Koseoglu-Imer, B. Keskinler, Techno-economic viability of innovative membrane systems in water and mass recovery from dairy wastewater, J. Memb. Sci. 458 (2014) 66-75. doi:10.1016/j.memsci.2014.01.058.

[79] T.Y. Cath, A.E. Childress, M. Elimelech, Forward osmosis: Principles, applications, and recent developments, J. Memb. Sci. 281 (2006) 70-87. doi:10.1016/j.memsci.2006.05.048.

[80] M.M. Ling, T. Chung, Novel dual-stage FO system for sustainable protein enrichment using nanoparticles as intermediate draw solutes, J. Memb. Sci. 372 (2011) 201-209. doi:10.1016/j.memsci.2011.02.003.

[81] M. Elsayed, A.E.F. Abomohra, P. Ai, K. Jin, Q. Fan, Y. Zhang, Acetogenesis and methanogenesis liquid digestates for pretreatment of rice straw: A holistic approach for efficient biomethane production and nutrient recycling, Energy Convers. Manag. 195 (2019) 447-456. doi:10.1016/j.enconman.2019.05.011.

[82] Y. Zhang, K. Nakagawa, M. Shibuya, K. Sasaki, T. Takahashi, T. Shintani, T. Yoshioka, E. Kamio, A. Kondo, H. Matsuyama, Improved permselectivity of forward osmosis membranes for efficient concentration of pretreated rice straw and bioethanol production, J. Memb. Sci. (2018). doi:10.1016/j.memsci.2018.08.046.

[83] J.B. McKinlay, C. Vieille, J.G. Zeikus, Prospects for a bio-based succinate industry, Appl. Microbiol. Biotechnol. 76 (2007) 727-740. doi:10.1007/s00253-007-1057-y.

[84] P. Khunnonkwao, K. Jantama, S. Kanchanatawee, S. Galier, H. Roux-de Balmann, A two steps membrane process for the recovery of succinic acid from fermentation broth, Sep. Purif. Technol. 207 (2018) 451-460. doi:10.1016/j.seppur.2018.06.056.

[85] J. Yih, A. Wahab, Z. Kang, N. Khairul, J. Jahim, J. Santanaraj, M. Shaiful, Recovery of succinic acid from fermentation broth by forward osmosis- assisted crystallization process, J. Memb. Sci. 583 (2019) 139-151. doi:10.1016/j.memsci.2019.04.036.

[86] A. Altaee, G. Zaragoza, A. Sharif, Pressure retarded osmosis for power generation and seawater desalination: Performance analysis, Desalination. 344 (2014) 108-115. doi:10.1016/j.desal.2014.03.022.

[87] Z. Lei, X. Li, T. Chung, The forward osmosis-pressure retarded osmosis ( FO-PRO ) hybrid system : A new process to mitigate membrane fouling for sustainable osmotic power generation, J. Memb. Sci. 559 (2018) 63-74. doi:10.1016/j.memsci.2018.04.036.

[88] H. Wang, Z.J. Ren, A comprehensive review of microbial electrochemical systems as a platform technology, Biotechnol. Adv. 31 (2013) 1796-1807. doi:10.1016/j.biotechadv.2013.10.001.

[89] X. Zhang, W. He, L. Ren, J. Stager, P.J. Evans, B.E. Logan, COD removal characteristics in air-cathode microbial fuel cells, Bioresour. Technol. 176 (2015) 2331. doi:10.1016/j.biortech.2014.11.001. 
[90] J. Liu, X. Wang, Z. Wang, Y. Lu, X. Li, Y. Ren, Integrating microbial fuel cells with anaerobic acidification and forward osmosis membrane for enhancing bio-electricity and water recovery from low-strength wastewater, Water Res. (2017). doi:10.1016/j.watres.2016.12.012.

[91] D. Pant, G. Van Bogaert, L. Diels, K. Vanbroekhoven, A review of the substrates used in microbial fuel cells (MFCs) for sustainable energy production, Bioresour. Technol. 101 (2010) 1533-1543. doi:10.1016/j.biortech.2009.10.017.

[92] M. Xie, L.D. Nghiem, W.E. Price, M. Elimelech, Toward Resource Recovery from Wastewater: Extraction of Phosphorus from Digested Sludge Using a Hybrid Forward Osmosis-Membrane Distillation Process, Environ. Sci. Technol. Lett. 1 (2014) 191195. doi:10.1021/ez400189z.

[93] A.J. Ansari, F.I. Hai, W.E. Price, L.D. Nghiem, Phosphorus recovery from digested sludge centrate using seawater-driven forward osmosis, Sep. Purif. Technol. 163 (2016) 1-7. doi:10.1016/j.seppur.2016.02.031.

[94] L. Chekli, Y. Kim, S. Phuntsho, S. Li, N. Ghaffour, T.O. Leiknes, H.K. Shon, Evaluation of fertilizer-drawn forward osmosis for sustainable agriculture and water reuse in arid regions, J. Environ. Manage. 187 (2017) 137-145. doi:10.1016/j.jenvman.2016.11.021.

[95] P. Nasr, H. Sewilam, Investigating the performance of ammonium sulphate draw solution in fertilizer drawn forward osmosis process, Clean Technol. Environ. Policy. 18 (2016) 717-727. doi:10.1007/s10098-015-1042-6.

[96] S. Phuntsho, H.K. Shon, T. Majeed, I. El Saliby, S. Vigneswaran, J. Kandasamy, S. Hong, S. Lee, Blended fertilizers as draw solutions for fertilizer-drawn forward osmosis desalination, Environ. Sci. Technol. 46 (2012) 4567-4575. doi:10.1021/es300002w.

[97] S. Zou, Z. He, Enhancing wastewater reuse by forward osmosis with self-diluted commercial fertilizers as draw solutes, Water Res. 99 (2016) 235-243. doi:10.1016/j.watres.2016.04.067.

[98] W. Suwaileh, D. Johnson, N. Hilal, Brackish water desalination for agriculture: Assessing the performance of inorganic fertilizer draw solutions, Desalination. 456 (2019) 53-63. doi:10.1016/j.desal.2019.01.014.

[99] J. Duan, E. Litwiller, S.H. Choi, I. Pinnau, Evaluation of sodium lignin sulfonate as draw solute in forward osmosis for desert restoration, J. Memb. Sci. 453 (2014) 463470. doi:10.1016/j.memsci.2013.11.029.

[100] M. Elimelech, W.A. Phillip, The future of seawater desalination: Energy, technology, and the environment, Science. 333 (2011) 712-717. doi:10.1126/science.1200488.

[101] R.L. McGinnis, M. Elimelech, Energy requirements of ammonia-carbon dioxide forward osmosis desalination, Desalination. 207 (2007) 370-382. doi:10.1016/j.desal.2006.08.012.

[102] N.T. Hancock, P. Xu, D.M. Heil, C. Bellona, T.Y. Cath, Comprehensive bench- and pilot-scale investigation of trace organic compounds rejection by forward osmosis, Environ. Sci. Technol. 45 (2011) 8483-8490. doi:10.1021/es201654k.

[103] S. Lee, C. Boo, M. Elimelech, S. Hong, Comparison of fouling behavior in forward osmosis (FO) and reverse osmosis (RO), J. Memb. Sci. 365 (2010) 34-39. doi:10.1016/j.memsci.2010.08.036.

[104] O.A. Bamaga, A. Yokochi, B. Zabara, A.S. Babaqi, Hybrid FO/RO desalination system: Preliminary assessment of osmotic energy recovery and designs of new FO membrane module configurations, Desalination. 268 (2011) 163-169. doi:10.1016/j.desal.2010.10.013.

[105] T.Y. Cath, N.T. Hancock, C.D. Lundin, C. Hoppe-Jones, J.E. Drewes, A multi-barrier 
osmotic dilution process for simultaneous desalination and purification of impaired water, J. Memb. Sci. 362 (2010) 417-426. doi:10.1016/j.memsci.2010.06.056.

[106] C.H. Tan, H.Y. Ng, A novel hybrid forward osmosis - nanofiltration (FO-NF) process for seawater desalination: Draw solution selection and system configuration, Desalin. Water Treat. 13 (2010) 356-361. doi:10.5004/dwt.2010.1733.

[107] E.S.P.B. V, A.G. Fane, A Review of Fouling and Fouling Control in Ultrafiltration, Desalination. 62 (1987) 117-136.

[108] W. Gao, H. Liang, J. Ma, M. Han, Z. lin Chen, Z. shuang Han, G. bai Li, Membrane fouling control in ultrafiltration technology for drinking water production: A review, Desalination. 272 (2011) 1-8. doi:10.1016/j.desal.2011.01.051.

[109] Q. Ge, J. Su, G.L. Amy, T.S. Chung, Exploration of polyelectrolytes as draw solutes in forward osmosis processes, Water Res. 46 (2012) 1318-1326. doi:10.1016/j.watres.2011.12.043.

[110] Y. Kim, J.H. Lee, Y.C. Kim, K.H. Lee, I.S. Park, S.J. Park, Operation and simulation of pilot-scale forward osmosis desalination with ammonium bicarbonate, Chem. Eng. Res. Des. 94 (2015) 390-395. doi:10.1016/j.cherd.2014.08.015.

[111] J.R. McCutcheon, R.L. McGinnis, M. Elimelech, A novel ammonia-carbon dioxide forward (direct) osmosis desalination process, Desalination. 174 (2005) 1-11. doi:10.1016/j.desal.2004.11.002.

[112] George W. Batcheider, Process for the demeneralization, 1965.

[113] D.N. Glew, Process for liquid recovery and solution concentration, 1965.

[114] M.L. Stone, C. Rae, F.F. Stewart, A.D. Wilson, Switchable polarity solvents as draw solutes for forward osmosis, Desalination. 312 (2013) 124-129. doi:10.1016/j.desal.2012.07.034.

[115] D.S. Wendt, C.J. Orme, G.L. Mines, A.D. Wilson, Energy requirements of the switchable polarity solvent forward osmosis (SPS-FO) water purification process, Desalination. 374 (2015) 81-91. doi:10.1016/j.desal.2015.07.012.

[116] R.L. McGinnis, N.T. Hancock, M.S. Nowosielski-Slepowron, G.D. McGurgan, Pilot demonstration of the $\mathrm{NH} 3 / \mathrm{CO} 2$ forward osmosis desalination process on high salinity brines, Desalination. 312 (2013) 67-74. doi:10.1016/j.desal.2012.11.032.

[117] S.K. Yen, F. Mehnas Haja N., M. Su, K.Y. Wang, T.S. Chung, Study of draw solutes using 2-methylimidazole-based compounds in forward osmosis, J. Memb. Sci. 364 (2010) 242-252. doi:10.1016/j.memsci.2010.08.021.

[118] D. Zhao, P. Wang, Q. Zhao, N. Chen, X. Lu, Thermoresponsive copolymer-based draw solution for seawater desalination in a combined process of forward osmosis and membrane distillation, Desalination. 348 (2014) 26-32. doi:10.1016/j.desal.2014.06.009.

[119] Q. Zhao, N. Chen, D. Zhao, X. Lu, Thermoresponsive magnetic nanoparticles for seawater desalination, ACS Appl. Mater. Interfaces. 5 (2013) 11453-11461. doi:10.1021/am403719s.

[120] A. Zhou, H. Luo, Q. Wang, L. Chen, T.C. Zhang, T. Tao, Magnetic thermoresponsive ionic nanogels as novel draw agents in forward osmosis, RSC Adv. 5 (2015) 1535915365. doi:10.1039/c4ra12102c.

[121] W. Suwaileh, D. Johnson, D. Jones, N. Hilal, An integrated fertilizer driven forward osmosis- renewables powered membrane distillation system for brackish water desalination: A combined experimental and theoretical approach, Desalination. 471 (2019) 114126. doi:10.1016/j.desal.2019.114126.

[122] Q. Ge, J. Su, T.S. Chung, G. Amy, Hydrophilic superparamagnetic nanoparticles: Synthesis, characterization, and performance in forward osmosis processes, Ind. Eng. Chem. Res. 50 (2011) 382-388. doi:10.1021/ie101013w. 
[123] M.M. Ling, T.S. Chung, Desalination process using super hydrophilic nanoparticles via forward osmosis integrated with ultrafiltration regeneration, Desalination. 278 (2011) 194-202. doi:10.1016/j.desal.2011.05.019.

[124] M.M. Ling, T.S. Chung, X. Lu, Facile synthesis of thermosensitive magnetic nanoparticles as "smart" draw solutes in forward osmosis, Chem. Commun. 47 (2011) 10788-10790. doi:10.1039/c1cc13944d.

[125] M.M. Ling, T.S. Chung, Surface-dissociated nanoparticle draw solutions in forward osmosis and the regeneration in an integrated electric field and nanofiltration System, Ind. Eng. Chem. Res. 51 (2012) 15463-15471. doi:10.1021/ie302331h.

[126] H. Han, J.Y. Lee, X. Lu, Thermoresponsive nanoparticles + plasmonic nanoparticles = photoresponsive heterodimers: Facile synthesis and sunlight-induced reversible clustering, Chem. Commun. 49 (2013) 6122-6124. doi:10.1039/c3cc42273a.

[127] A. Razmjou, M.R. Barati, G.P. Simon, K. Suzuki, H. Wang, Fast deswelling of nanocomposite polymer hydrogels via magnetic field-induced heating for emerging FO desalination, Environ. Sci. Technol. 47 (2013) 6297-6305. doi:10.1021/es4005152.

[128] S. Zou, Z. He, Electrodialysis recovery of reverse-fluxed fertilizer draw solute during forward osmosis water treatment, Chem. Eng. J. 330 (2017) 550-558. doi:10.1016/j.cej.2017.07.181.

[129] B.S. Frank, Desalination of sea water, 1972. doi:10.1016/0375-6505(85)90011-2.

[130] R. Alnaizy, A. Aidan, M. Qasim, Copper sulfate as draw solute in forward osmosis desalination, J. Environ. Chem. Eng. 1 (2013) 424-430. doi:10.1016/j.jece.2013.06.005.

[131] R. Alnaizy, A. Aidan, M. Qasim, Draw solute recovery by metathesis precipitation in forward osmosis desalination, Desalin. Water Treat. 51 (2013) 5516-5525. doi:10.1080/19443994.2013.770238.

[132] C. Boo, M. Elimelech, S. Hong, Fouling control in a forward osmosis process integrating seawater desalination and wastewater reclamation, J. Memb. Sci. 444 (2013) 148-156. doi:10.1016/j.memsci.2013.05.004.

[133] B. Aftab, Y. Sik, J. Cho, J. Hur, Targeted removal of organic foulants in land fill leachate in forward osmosis system integrated with biochar/activated carbon treatment, Water Res. 160 (2019) 217-227.

[134] M. Qasim, N.A. Darwish, S. Sarp, N. Hilal, Water desalination by forward (direct) osmosis phenomenon: A comprehensive review, Desalination. 374 (2015) 47-69. doi:10.1016/j.desal.2015.07.016.

[135] P.S. Goh, W.J. Lau, M.H.D. Othman, A.F. Ismail, Membrane fouling in desalination and its mitigation strategies, Desalination. 425 (2018) 130-155. doi:10.1016/j.desal.2017.10.018.

[136] T. Xiao, P. Dou, J. Wang, J. Song, Y. Wang, X. Li, T. He, Concentrating greywater using hollow fiber thin film composite forward osmosis membranes : Fouling and process optimization, Chem. Eng. Sci. 190 (2018) 140-148. doi:10.1016/j.ces.2018.06.028.

[137] A.H. Hawari, A. Al-qahoumi, A. Ltaief, S. Zaidi, A. Altaee, Dilution of seawater using dewatered construction water in a hybrid forward osmosis system, J. Clean. Prod. 195 (2018) 365-373. doi:10.1016/j.jclepro.2018.05.211.

[138] B.K. Sovacool, Cornucopia or curse? Reviewing the costs and benefits of shale gas hydraulic fracturing (fracking), Renew. Sustain. Energy Rev. 37 (2014) 249-264. doi:10.1016/j.rser.2014.04.068.

[139] S. Islam, K. Touati, S. Rahaman, Feasibility of a hybrid membrane-based process (MF-FO-MD) for fracking wastewater treatment, Sep. Purif. Technol. 229 (2019) 
115802.

[140] K. Sardari, P. Fyfe, S.R. Wickramasinghe, Integrated electrocoagulation - Forward osmosis - Membrane distillation for sustainable water recovery from hydraulic fracturing produced water, J. Memb. Sci. 574 (2019) 325-337. doi:10.1016/j.memsci.2018.12.075.

[141] B.K. Pramanik, F.I. Hai, F.A. Roddick, Ultraviolet/persulfate pre-treatment for organic fouling mitigation of forward osmosis membrane: possible application in nutrient mining from dairy wastewater, Sep. Purif. Technol. (2019). doi:10.1016/j.seppur.2019.02.016.

[142] K. Sivagami, K.P. Sakthivel, I.M. Nambi, Advanced oxidation processes for the treatment of tannery wastewater, J. Environ. Chem. Eng. 6 (2018) 3656-3663. doi:10.1016/j.jece.2017.06.004.

[143] D. Jovanov, B. Vujić, G. Vujić, Optimization of the monitoring of landfill gas and leachate in closed methanogenic landfills, J. Environ. Manage. 216 (2018) 32-40. doi:10.1016/j.jenvman.2017.08.039.

[144] S.M. Iskander, S. Zou, B. Brazil, J.T. Novak, Z. He, Energy consumption by forward osmosis treatment of landfill leachate for water recovery, Waste Manag. 63 (2017) 284-291. doi:10.1016/j.wasman.2017.03.026.

[145] B.D. Coday, T.Y. Cath, Forward osmosis: Novel desalination of produced water and fracturing flowback, J. Am. Water Works Assoc. 106 (2014) 37-38. doi:10.5942/jawwa.2014.106.0016.

[146] J.J. Qin, K.A. Kekre, M.H. Oo, G. Tao, C.L. Lay, C.H. Lew, E.R. Cornelissen, C.J. Ruiken, Preliminary study of osmotic membrane bioreactor: Effects of draw solution on water flux and air scouring on fouling, Water Sci. Technol. 62 (2010) 1353-1360. doi:10.2166/wst.2010.426.

[147] K. Xiao, S. Liang, X. Wang, C. Chen, X. Huang, Current state and challenges of fullscale membrane bioreactor applications: A critical review, Bioresour. Technol. 271 (2019) 473-481. doi:10.1016/j.biortech.2018.09.061.

[148] A. Trapote, A. Albaladejo, P. Simón, Energy consumption in an urban wastewater treatment plant: the case of Murcia Region (Spain), Civ. Eng. Environ. Syst. 31 (2014) 304-310. doi:10.1080/10286608.2013.866106.

[149] R. Lambrechts, M.S. Sheldon, Performance and energy consumption evaluation of a fertiliser drawn forward osmosis (FDFO) system for water recovery from brackish water, Desalination. 456 (2019) 64-73. doi:10.1016/j.desal.2019.01.016.

[150] D.J. Lee, M.H. Hsieh, Forward osmosis membrane processes for wastewater bioremediation: Research needs, Bioresour. Technol. 290 (2019) 121795. doi:10.1016/j.biortech.2019.121795.

[151] M. Raffin, E. Germain, S. Judd, Wastewater polishing using membrane technology: A review of existing installations, Environ. Technol. 34 (2013) 617-627. doi:10.1080/09593330.2012.710385.

[152] D.L. Shaffer, N.Y. Yip, J. Gilron, M. Elimelech, Seawater desalination for agriculture by integrated forward and reverse osmosis: Improved product water quality for potentially less energy, J. Memb. Sci. 415-416 (2012) 1-8. doi:10.1016/j.memsci.2012.05.016. 